\title{
HOW DO MAGELLANIC PENGUINS COPE WITH VARIABILITY IN THEIR ACCESS TO PREY?
}

\author{
Rory P. Wilson,${ }^{1,2,6}$ J. Alejandro Scolaro, ${ }^{3}$ David Grémillet, ${ }^{4}$ Mandy A. M. Kierspel, ${ }^{2}$ \\ Sonia Laurenti,${ }^{3}$ Jorge Upton, ${ }^{3}$ Hector Gallelli,${ }^{3}$ Flavio Quintana, ${ }^{3}$ Esteban Frere, ${ }^{5}$ \\ Gabriele Müller, ${ }^{1}$ Marion Thor Straten, ${ }^{1}$ And Ilka Zimmer ${ }^{1}$ \\ ${ }^{1}$ School of Biological Sciences, Institute of Environmental Sustainability, University of Wales, \\ Singleton Park, Swansea SA2 8PP, UK \\ ${ }^{2}$ Leibniz-institut für Meereswissenschaften, Düsternbrooker Weg 20, D-24105 Kiel, Germany \\ ${ }^{3}$ Centro Patagonico, Boulevard Brown s/n, Puerto Madryn, Chubut, Argentina \\ ${ }^{4}$ Centre d'Ecologie et Physiologie Energétiques, CNRS, 23 Rue Becquerel, F-67087 Strasbourg Cedex 2, France \\ ${ }^{5}$ Centro de Investigaciones Puerto Deseado, Universidad Nacional de la Patagonia Austral, CONICET, Avenida Lotufo s/n, \\ 9050 Puerto Deseado, Argentina
}

\begin{abstract}
Movements of animals provisioning offspring by central place foraging extend from short, highly local trips where food is brought back essentially unchanged from its normal condition to extensive interseasonal movement where the offspring are nourished from body reserves built up during the adult's absence from the breeding site. Here, appropriate strategies for maximizing lifetime reproductive success depend on the abundance and location of prey in relation to breeding sites and the energetics and speed of travel of the animal. Magellanic Penguins Spheniscus magellanicus undertake central place movements that are particularly variable during the incubation period; trips may last from a single day to over three weeks depending on colony locality. We reasoned that site-specific variability in prey distribution and abundance is responsible for this. Remote-sensing systems attached to 92 penguins from six different colonies over the species distributional range over the Patagonian Shelf were used to determine space use and foraging patterns in an attempt to understand the observed patterns. Birds in the north and south of the latitudinal range were essentially monophagic, feeding primarily on anchovies Engraulis anchoita and sprats Sprattus fuegensis, respectively, both species that are to be found relatively close to the colonies. Penguins in the center of the distributional range, where these pelagic school fish prey are essentially absent at that time of the year, traveled either north or south, to the same regions utilized by their conspecifics, presumably to exploit the same prey. A simple model is used to clarify patterns and can be used to predict which movement strategy is likely to be best according to colony location. During chick rearing, southerly movement of anchovies and northerly movement of sprats mean that Magellanic Penguins in the center of the distributional range may benefit, although the abundance of these fish is considered to be less than that closer to the Magellanic Penguin range limits. The extensive time involved in the foraging trips during incubation coupled with the postulated poorer prey conditions during the chick-rearing phase may help explain why Magellanic Penguin colony sizes in the center of the range are not elevated.
\end{abstract}

Key words: central place foraging; energy reserves; Magellanic Penguins; migration; Patagonian Shelf; prey variability; Spheniscus magellanicus.

\section{INTRODUCTION}

The distinction between central place foraging trips (sensu, Orians and Pearson 1979) and migration (e.g., Berthold 2003, Rappole et al. 2003) is less obvious than the literature would imply. Implicit in central place foraging is the transfer of energy from a distant to a proximal site (e.g., Jackson 2001), relevant with respect to ecological subsidies (cf. Palumbi 2003), and often this energy takes the form of food that is used to provision offspring (e.g., Leopold et al. 1996, Max-

Manuscript received 9 August 2004; accepted 12 October 2004; final version received 13 December 2004. Corresponding Editor: B. P. Kotler.

${ }^{6}$ E-mail: r.p.wilson@swansea.ac.uk well and Calver 1998). Altricial birds are a good example of this (Brodin and Jonsson 2003). However, energy may also be transferred to the young in a variety of forms and over a series of time scales (Bonnet et al. 1999). Body fat, for example, can be used to provision offspring in the form of milk, as seen with many seals. For animals that build up body tissue to provision their young, the further distinction between "investment" and "capital" breeders (e.g., Jonsson 1997), as applied to pinnipeds, highlights difficulties in defining the difference between central place foraging and migration. Investment breeders, such as eared seals, provision their young with milk, with body fat and protein stores being restocked during foraging trips lasting a 


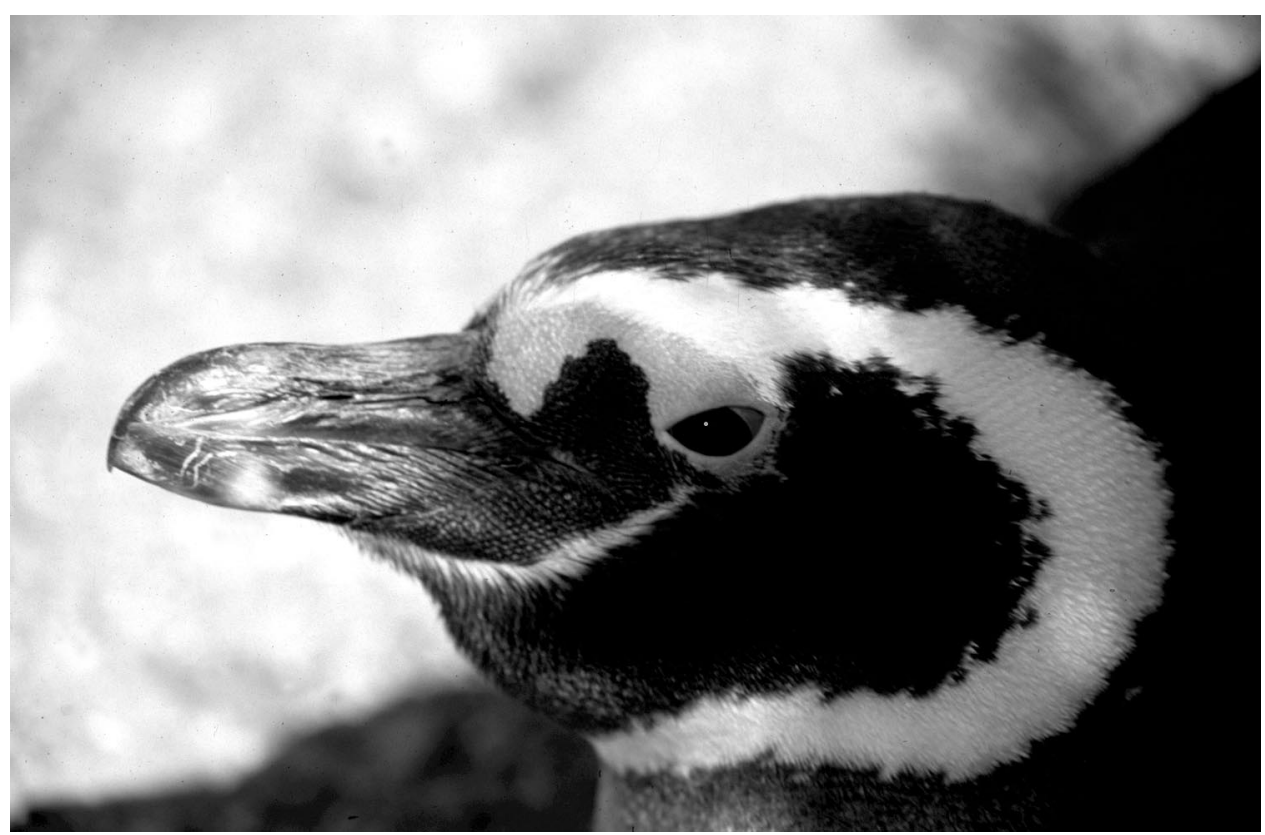

Plate 1. The Magellanic Penguin Spheniscus magellanicus is one of four species in its genus. It breeds on the coasts of South America, with its range extending from about Peninsula Valdes, Argentina, around Cape Horn to Algarrobo in central Chile. Photo credit: R. P. Wilson.

few days (Boyd 2000, Beck et al. 2003). Capital breeders, such as elephant seals, do not engage in foraging trips during the weaning period, relying exclusively on fat stores accumulated during the extensive "nonbreeding" season, to provision their young (Boyd 2000, McMahon and Hindell 2003). One could argue here that the non-breeding period is, therefore, little more than an extended foraging trip (cf. Bonnet et al. 1999, Jonsson et al. 1999). Similarly, many migratory and non-migratory species of diverse animal groups improve body condition between breeding seasons, transferring energy from one time period to another, so that their reproductive success is enhanced (e.g., Pietiainen and Kolunen 1993, Bonnet et al. 2001; cf. Kinnison et al. 2003). In short, the essence behind differences in definitions of central place foraging and migration is little more than the degree to which an appropriate food source is remote from the breeding site (Perez-Tris and Telleria 2002), because this affects cost, how long it takes for the animal to move between the two sites, and whether single or multiple trips are made between breeding attempts. The relative benefits of movement on any scale depend on the rate at which energy must be taken from one site to another (Benoit et al. 1993, Korpimake et al. 1994), and ultimately the extent to which lifetime reproductive success can be maximized by animals spending an appreciable proportion of their time in one location while their offspring is at another (Drent et al. 2003, Hedenström 2003).

During their annual cycle Magellanic Penguins Spheniscus magellanicus (see Plate 1) show a variety of forms of movement. Immediately after breeding, the birds embark on an extended (from three to six week) foraging trip from their colonies to fatten up before returning to molt (Williams 1995). After the molt these birds migrate many hundreds of kilometers to the north (Stokes and Boersma 1998, Pütz et al. 2000) and remain away from their breeding colonies at this time for about six months. During the breeding season foraging trips are much shorter (Boersma et al. 2002, Pütz et al. 2002) although there is a clear distinction between the length of foraging trips between the incubation and chickrearing phases. Foraging trips during chick rearing are rarely longer than two days (Radl and Culik 1999, Walker and Boersma 2003), whereas during the incubation period, trips might last up to three weeks (Wilson et al. 1995c, Walker and Boersma 2003; cf. Pütz et al. 2002). It can be assumed that the length of time that penguins remain away from their breeding colonies during these various forays depends, ultimately, on maximizing lifetime reproductive success (McNamara and Houston 1996). Proximately, however, any foray away from the colony must result in a net energy gain to the penguin, and the appropriate distances moved and times spent away will depend on a number of factors (cf. Henry et al. 2002): the rate of energy gain in the foraging area, the distance between the colony and the foraging area and the time it takes to cover the distance, the energy expended during travel and foraging, and the overall rate of energy delivery needed to the breeding site, whether this be in the form of a fattened up adult or as food for the brood (cf. Markman et al. 2004). For breeding animals it is ultimately the 
rate of energy delivery to the brood in relation to brood requirements that determines whether breeding animals should continue to breed or abandon their attempt in any given year (cf. Ropert-Coudert et al. 2004). Given the potential for variability in these parameters, particularly as regards distances and rate of energy acquisition (dependent on prey availability), we would expect a bird such as the Magellanic Penguin, with its large latitudinal range (Williams 1995), to have considerable variability in its foraging patterns; although we might expect solutions to be optimized for maximizing reproductive success.

We examined the behavior of Magellanic Penguins undertaking the extended foraging trips during the incubation phases at five different sites over almost the full latitudinal range of this species, extending from about $43^{\circ}$ to $54^{\circ} \mathrm{S}$ on the east coast of South America (Williams 1995). We hypothesized that the length of time that the penguins would stay away from their colonies during incubation period foraging trips would be related to the distance between the colonies and the food source as well as to the prey densities at the foraging site. We did not measure the distribution of the food source and prey densities directly, but inferred these from patterns of activity of birds at sea as derived from a wide variety of data storage tags carried by the birds. Key activities include time spent traveling to foraging sites and time spent at foraging sites. Using a steady state approach, where we assumed that penguin body mass loss during incubation together with energy expenditure during the foraging trip must be balanced with the energy acquired during the foraging trip, we present a simple model to explain patterns of foraging in Magellanic Penguins. We explain how derived prey density in relation to distance from the colony leads to variation in foraging trip length, and predict that the maximum time a foraging bird may stay away from the incubating partner before starvation leads to nest desertion (and brood loss) will ultimately help us understand penguin distribution down the coast of Argentina.

\section{Materials And Methods}

\section{Study areas}

Magellanic Penguins occur in colonies distributed down the coast of Argentina from about $42^{\circ} \mathrm{S}$ to almost $55^{\circ} \mathrm{S}$ latitude (Fig. 1). Field work was conducted on penguins during the incubation period between October and December 1994, October and December 1996, and November and December 1997 at five sites. These sites were: San Lorenzo $\left(42^{\circ} 04^{\prime} \mathrm{S}, 63^{\circ} 21^{\prime} \mathrm{W}\right)$, Punta Loberia $\left(44^{\circ} 35^{\prime} \mathrm{S}, 65^{\circ} 22^{\prime} \mathrm{W}\right)$, the area around San Julian $\left(49^{\circ} 16^{\prime} \mathrm{S}, 67^{\circ} 42^{\prime} \mathrm{W}\right)$, and Cabo Virgenes $\left(52^{\circ} 24^{\prime} \mathrm{S}\right.$, $68^{\circ} 26^{\prime} \mathrm{W}$ ), all located on mainland Argentina, as well as at New Island $\left(51^{\circ} 42^{\prime} \mathrm{S}, 61^{\circ} 16^{\prime} \mathrm{W}\right)$ in the Falklands/ Malvinas (Fig. 2). Field work was also conducted on penguins during the chick-rearing period (from the end of November through December) between 1997 and 2003 at four sites; San Lorenzo, around Puerto Deseado $\left(47^{\circ} 45^{\prime} \mathrm{S}, 65^{\circ} 63^{\prime} \mathrm{W}\right)$, and around San Julian and Cabo Virgenes (Fig. 2).

\section{Deployment of devices attached to animals}

Fifty-one Magellanic Penguins were equipped with data loggers (see Appendix A for information on all equipment used in this study) to record their movements and foraging behavior during the incubation period (Table 1). A further 41 birds were equipped during the chick-rearing period. Results from 10 of the birds equipped with data loggers during incubation (individuals fitted at San Lorenzo during 1994) have already been presented by Wilson et al. (1995c) but enhance the data set gained during 1996, and so, for completeness, are briefly considered here in a broader context. During 1994, penguins were only equipped with single channel global location sensors (Appendix A); however, during 1996, birds were fitted with global location sensors and one of five different multiple channel loggers that recorded depth as well as light intensity (Appendix A).

\section{Incubating penguins}

During October, Magellanic Penguins incubating eggs or penguins engaged in nest building were captured and restrained, using the technique described in Wilson (1997), while being fitted with loggers (Table 1) to their lower back (dorsal mid line) using tape (Wilson et al. 1997) so as to minimize drag (Bannasch et al. 1994). The animals were then released at the nest. Checks were made to recover the animals and their devices at variable intervals of between one and 50 days after deployment. This period could not be standardized due to the problem of attempting, with limited manpower, to equip and recover penguins virtually simultaneously at five different colonies spaced over the full latitudinal range.

Upon recovery of the birds, devices were removed and the data downloaded onto a computer. Nest attendance patterns of the penguins were easily recognized by substantial decreases in both light intensity and general activity recorded by the loggers when the birds entered their burrows. Information resulting from these loggers during incubation in 1996 is used specifically to determine foraging locations as well as to elucidate patterns of depth use according to colony. Bird movements were determined using the global location sensing method explained in Wilson et al. 1992 (cf. Wilson et al. 1992, Hill 1994, Welch and Eveson 1999, Hill and Braun 2001, Phillips et al. 2004, and Ekstrom 2004; see Appendix B.)

Depth utilization by penguins was analyzed using MULTITRACE and ANDIVE (Jensen Software Systems, Laboe, Germany) and histograms were derived for total time at each depth per specified time period. To avoid problems with pseudoreplication, the per- 


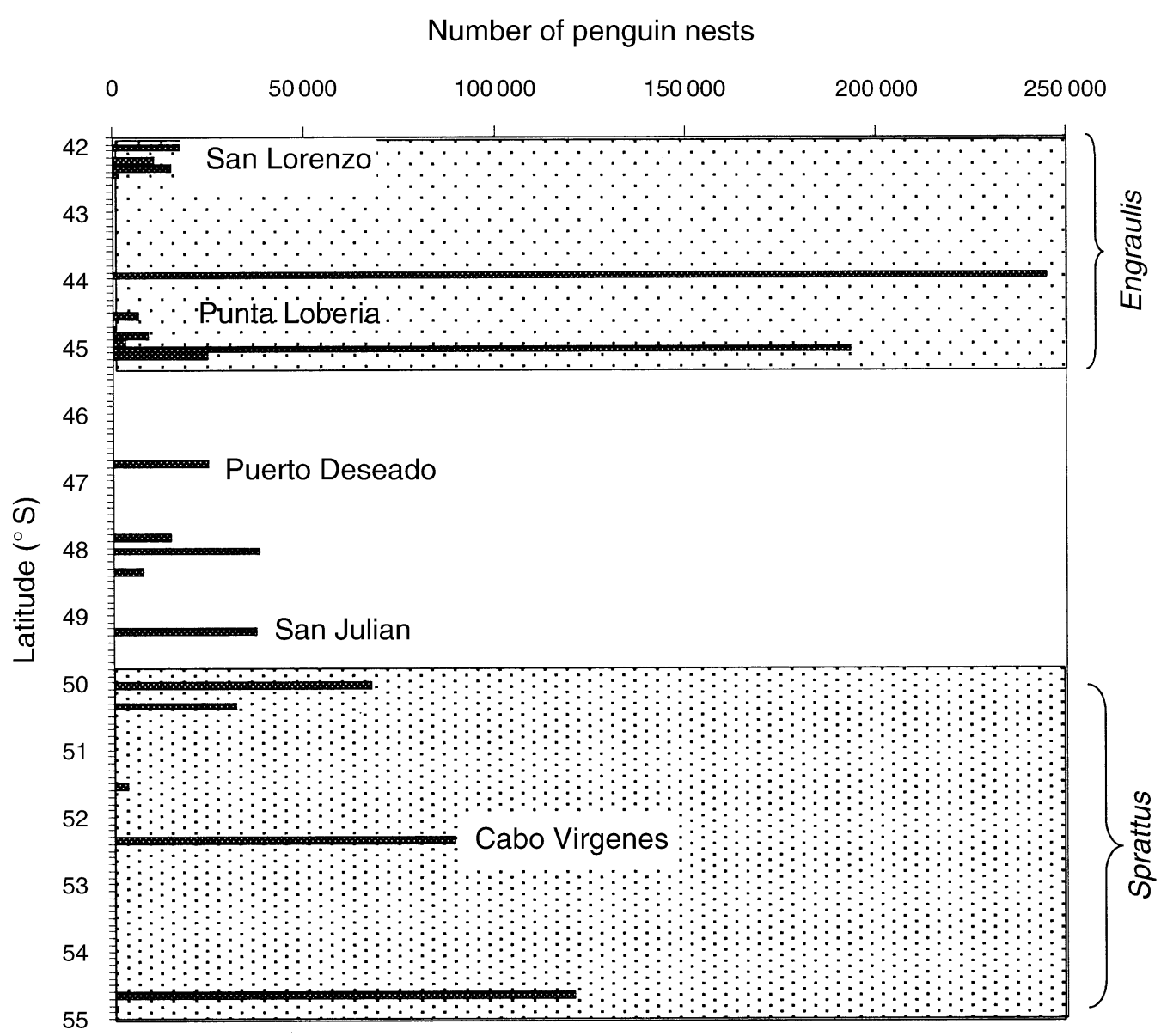

FIG. 1. Numbers of Magellanic Penguin nests in the various colonies (summed for $0.1^{\circ} \mathrm{S}$ latitude intervals) down the Patagonian coast. To standardize, penguin abundance data are taken from Yorio et al. (1998) (cf. Borboroglu et al. 2002) although it should be noted that substantial increases have occurred in the northern colonies since the time the area was surveyed. The approximate distributions of the two major prey types during September/October are also shown.

centage time spent at each depth was calculated for each individual bird; these values were then combined over all depth ranges for all individual birds from each colony before the total was reduced again to a percentage.

\section{Chick-rearing penguins}

Between 1997 and 2003, 41 Magellanic Penguins that were brooding small chicks were equipped with loggers (Table 1). Devices were fitted to the birds using the methods described but were recovered after a single foraging trip, usually a duration of less than two days. These devices were used to determine depth use by the penguins from the different colonies. Bird locations were not determined. Depth data were analyzed using ANDIVE WIN (Jensen Software Systems) and were assessed to determine traveling dives and the depths at which birds spent extended time (Appendix C). The calculated overall percentage extended time at depth (generally related to foraging depths; see Appendix C) for every single dive was gridded (employing a point
Kriging procedure using a linear variogram model; Surfer Version 9, Golden Software, Golden, Colorado, USA) against time of day and depth before producing a topographic plot for birds from each locality that indicated how birds used depth to forage according to time of day.

\section{Dietary studies}

The diet of birds was studied during two main periods: during October 1996 at San Lorenzo, Punta Loberia, San Julian, and Cabo Virgenes, and during December 1997 at San Lorenzo, San Julian, and Cabo Virgenes. Birds were caught as they returned to shore from the sea in the afternoon or early evening and their stomachs were flushed using the method described in Wilson (1984). Birds were only flushed once to minimize disturbance, after which they were released in the colonies. Samples were examined on site within 12 hours. Where possible, fish and squid total lengths were measured directly. Otherwise prey length was calcu- 


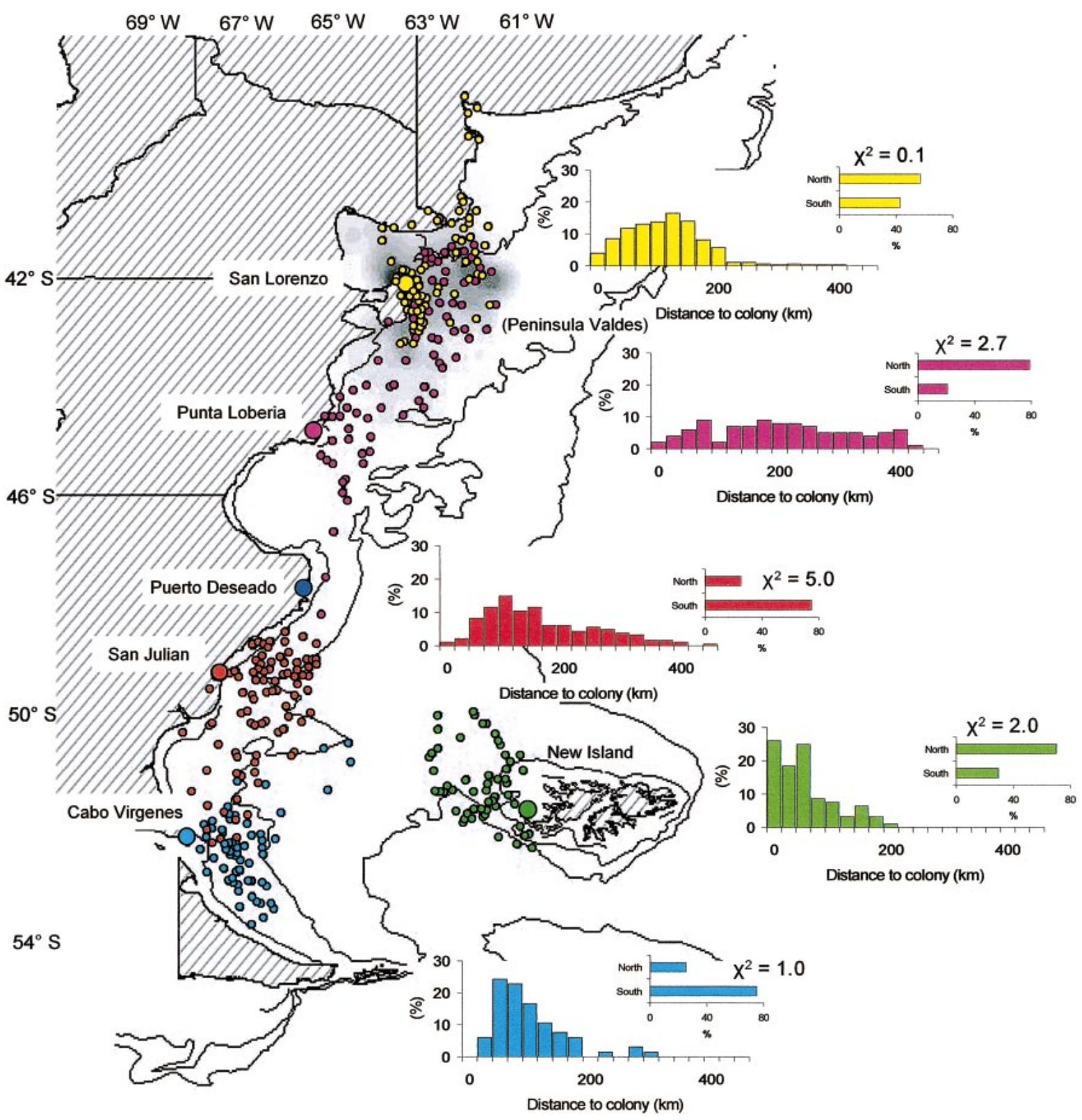

FIG. 2. Map of the study area showing position of the colonies (large colored dots on land) where Magellanic Penguins were equipped with devices. Types and numbers of devices deployed are in Table 1. Smaller dots (primarily at sea; those on land indicate an error in position estimation) show the daily positional fixes of birds tracked during the 1996 incubation period, with different colors corresponding to birds from different colonies. The shaded area around Peninsula Valdés indicates the relative densities of birds from Punta Norte during the 1994 incubation period (Wilson et al. 1995c). Frequencies of distances of the positional fixes from the colonies are shown as color-coded bar charts; smaller graphs with the double bars inset in these show the percentage of fixes to the north and south of the different colonies. Chi-square values consider whether the number of birds from each particular colony moving overall north or south (we calculated for each individual a mean maximum latitudinal distance to the colony latitude derived from all foraging trips made by that bird) relative to the colony differs from that expected by chance. The predominant movement is north in the northern mainland colonies, and south in the southern mainland colonies.

lated using otolith length or beak rostral length measurements using appropriate equations (Appendix D).

\section{Model of site-specific prey availability}

We sought to allude to putative differences in prey availability for the different colonies by creating a sim- ple model based on what is known about penguin energetics and foraging behavior. We assumed that birds undertake their foraging trips in order to maintain body condition (i.e., the energy gained during foraging is equaled by that expended over the full cycle). This is 
TABLE 1. Site of deployment and type of device fitted to Magellanic Penguins between October and December for the years from 1994 to 2003 inclusive.

\begin{tabular}{|c|c|c|c|c|}
\hline $\begin{array}{l}\text { Site and } \\
\text { year }\end{array}$ & $\begin{array}{l}\text { Type of } \\
\text { device } \dagger\end{array}$ & Period & $\begin{array}{c}\text { No. } \\
\text { deployed }\end{array}$ & $\begin{array}{c}\text { No. } \\
\text { recovered }\end{array}$ \\
\hline \multicolumn{5}{|c|}{ San Lorenzo } \\
\hline 1994 & GLS & incubation & 10 & 10 \\
\hline 1996 & DK 600 & incubation & 12 & 11 \\
\hline 2002 & LTD_100 & chick-rearing & 4 & 4 \\
\hline 2003 & E \& O log & chick-rearing & 9 & 9 \\
\hline \multicolumn{5}{|c|}{ Punta Loberia } \\
\hline 1996 & GLS & incubation & 2 & 2 \\
\hline 1996 & DK 600 & incubation & 4 & 4 \\
\hline \multicolumn{5}{|c|}{ Puerto Deseado } \\
\hline 2000 & Mk VI & chick-rearing & 5 & 5 \\
\hline \multicolumn{5}{|c|}{ San Julian } \\
\hline 1996 & GLS & incubation & 2 & 2 \\
\hline 1996 & DK 600 & incubation & 4 & 3 \\
\hline 1999 & LTD_100 & chick-rearing & 3 & 3 \\
\hline 2000 & DK 600 & chick-rearing & 4 & 4 \\
\hline \multicolumn{5}{|c|}{ Cabo Virgenes } \\
\hline 1996 & DK 600 & incubation & 6 & 4 \\
\hline 1999 & DK 600 & chick-rearing & 6 & 6 \\
\hline 2000 & DK 600 & chick-rearing & 10 & 10 \\
\hline \multicolumn{5}{|c|}{ New Island } \\
\hline 1996 & Zelcon tag & incubation & 8 & 8 \\
\hline 1996 & $\mathrm{Mk} \mathrm{V}$ & incubation & 3 & 3 \\
\hline Total & & & 92 & 88 \\
\hline
\end{tabular}

$\dagger$ See Appendix A for information on all devices used in this study.

a simple steady-state formulation although we cannot discount that penguins might be maximizing a complex fitness function that is a positive function of energy gain and a negative function of risk of abandonment and predation. In a general sense we assume here that foraging trip length is mirrored by incubation shift length (since partners switch roles, with one bird being on the nest while the other is at sea) so the energy accrued during the foraging trip must cover the energy expended during the period on land as well as the period at sea. The formulation for the energy expended over a full foraging/incubating cycle is

$$
E_{\mathrm{tot}}=\left(E_{\text {lnd }} \times T_{\text {lnd }}\right)+\left(E_{\mathrm{wtr}} \times T_{\mathrm{wtr}}\right)
$$

where $E_{\text {tot }}$ is the total energy expended, $E_{\text {lnd }}$ and $E_{\text {wtr }}$ are the energies expended per unit time on land and in water, respectively, and $T_{\text {Ind }}$ and $T_{\text {wtr }}$ are the times spent on land and at sea, respectively. In this application $T_{\text {lnd }}$ $=T_{\text {wtr }}$ because the birds returning to the colony from foraging at sea quickly replace the incubating or brooding partner that, in turn, goes immediately to sea to feed. Although during the incubation period on land metabolic rate is liable to be fairly constant, energy expenditure in the water is expected to vary according to activity. More specifically, energy expenditure depends on how much time the penguins spend engaged in underwater swimming or resting between dives at the water surface. The three major activities of pen- guins that are undergoing foraging trips are traveling, foraging, and resting at the sea surface for extended periods (Wilson and Wilson 1990, 1995, Wilson 1995), with each of these activities involving different proportions of time allocated to time underwater and to time at the surface. However, penguins only travel (appreciably) and forage when they are underwater (Wilson 1985). Thus, the energy expended for the time at sea can be refined to

$$
\begin{aligned}
E_{\text {sea }}= & \left\{T_{\text {trv }}\left[\left(E_{\text {uwtr }} \times \%_{\text {uwtr }}\right)+\left(E_{\text {surf }} \times \%_{\text {surf }}\right)\right] / 100\right\} \\
& +\left\{T_{\text {for }}\left[\left(E_{\text {uwtr }} \times \%_{\text {uwtr }}\right)+\left(E_{\text {surf }} \times \%_{\text {surf }}\right)\right] / 100\right\} \\
& +\left(T_{\text {res }} \times E_{\text {surf }}\right)
\end{aligned}
$$

where $T_{\text {trv }}, T_{\text {for }}$, and $T_{\text {res }}$ are the total times spent engaged in traveling, foraging, and resting during a foraging trip (all of which can be derived from the logger data); $E_{\text {uwtr }}$ and $E_{\text {surf }}$ are the energy expenditures per second during swimming underwater and resting at the surface, respectively; and $\%_{\text {uwtr }}$ and $\%_{\text {surf }}$ are the percentage times dedicated to swimming underwater and resting at the surface for each of the three major activities.

In order to convert the energy expended during a single foraging/incubating cycle into a total mass of food ingested during the foraging period $(M)$ we need to divide the $E_{\text {tot }}$ by the energetic value of the normal prey $\left(\mathrm{EV}_{\text {prey }}\right)$ multiplied by the assimilation efficiency of the penguins (AE) so that

$$
M=E_{\text {tot }} /\left(\mathrm{EV}_{\text {prey }} \times \mathrm{AE}\right) .
$$

Finally, the rate of prey ingestion $(\Delta I)$ can be calculated by dividing the calculated total mass of food ingested by the total time underwater committed to foraging during the trip so that

$$
\Delta I=M /\left(T_{\text {for }} \times \%_{\text {uwtr }}\right) .
$$

We combine the above terms in a general model where the number of days spent traveling to near or distant foraging zones may be varied at will, as can the number of days actually spent in the foraging zone. Predictions for the putative rate of prey ingestion $(\Delta I)$ derived for the various time allocation scenarios can be related to that actually observed.

In addition to the general formulation, we assume that the resting metabolic rate for the Magellanic Penguin may be approximated by that determined for the conspecific Humboldt Penguin Spheniscus humboldti in its thermoneutral zone. This is $3.77 \mathrm{~J} \cdot \mathrm{s}^{-1} \cdot \mathrm{kg}^{-1}$ (LunaJorquera 1996), which translates into $15.1 \mathrm{~J} / \mathrm{s}$ for a 4 kg Magellanic Penguin (Gandini et al. 1992). It has been shown that penguins in general tend to swim at speeds resulting in their lowest cost of transport (Culik et al. 1994b), and indeed, mass-specific power requirements for swimming at this lowest cost of transport are remarkably similar between species (Culik et al. $1994 b$ ). Here, we use the value of $50.7 \mathrm{~J} / \mathrm{s}$, being the value calculated for a $4 \mathrm{~kg}$ Humboldt Penguin by Luna- 
Jorquera and Culik (2000) using gas respirometry. Luna-Jorquera and Culik also provide values for resting metabolic rate for Humboldt Penguins in water of 23.6 J/s. Similar values obtained using the doubly labeled water methodology of Nagy et al. (1984) for the congeneric African Penguin Spheniscus demersus lend credibility to these estimates.

The normal underwater swim speed for the Magellanic Penguin is taken to be $1.77 \mathrm{~m} / \mathrm{s}$ (Wilson et al. 2002) and the ratio of underwater swimming to surface pauses assumed to be 76:24 for both traveling and foraging Magellanic Penguins (Wilson et al. 2004). The distance covered by foraging birds on the first and last days at sea, which was significantly greater than on other days, was assumed to be due to the animals traveling and was taken to be $79.1 \mathrm{~km}$. This would have taken about 12.4 hours to cover at an average speed of $1.34 \mathrm{~m} / \mathrm{s}$ (which takes into account the underwater swimming speeds and the relative times allocated to surface rests and subsurface traveling). This rate of displacement is used to calculate times allocated for birds from different colonies to travel to the different foraging zones. We assume that once the birds reached their respective foraging zones, they allocated 13 hours of the daily 24 hours to active foraging (cf. Simeone 2003), penguins being restricted to foraging (but not traveling) exclusively by the availability of light (Wilson et al. 1993). Traveling, rather than foraging, behavior was apparent by examination of the depths used by birds. Traveling birds stayed within $10 \mathrm{~m}$ of the surface while foraging birds regularly descended below this level (Wilson 1995). Once in the foraging area, birds are assumed to rest at night at the water surface. Finally, we assumed that penguins from all colonies fed on prey with an energy content of $5.5 \mathrm{MJ} / \mathrm{kg}$ wet mass (SAFIRI 1980, Fitzpatrick et al. 1988) and had an assimilation efficiency of $77 \%$ (Cooper 1977).

\section{RESULTS}

Of a total of 92 devices deployed on Magellanic Penguins, four were not recovered (4\%), all of these losses occurring during the incubation phase when birds were equipped for weeks rather than days. One of these had been fitted to a female occupying a nest at Cabo Virgenes with a male, although no eggs were present at the nest. Two of the remaining three lost units were placed on females incubating one egg and two eggs at San Julian and San Lorenzo, respectively. The final bird was a male incubating two eggs at Cabo Virgenes. In all cases except that at San Lorenzo, the well-being of the nest was assured during at least two subsequent checks although the birds equipped with devices were not found because their partners without devices were at the nest. Manpower limitations and logistic difficulties made it impossible to check these sites more than three times to recover the units although we have no reason to believe that the nests were abandoned. The site at San Lorenzo was checked on nu-

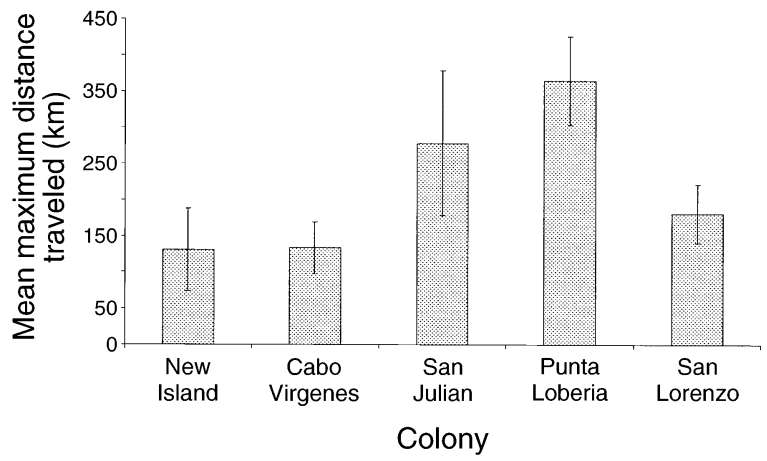

FIG. 3. Mean maximum distance over the Patagonian Shelf traveled by Magellanic Penguins from different colonies within the study area. One value is used for each individual (the number of individuals is shown in Table 1); where more than one foraging trip was recorded for any individual, a mean of the maxima recorded for this individual was used. Error bars represent mean $\pm \mathrm{SD}$.

merous occasions to reveal only the unequipped partner until the nest was eventually found deserted. It is unlikely that any birds with devices carried the units for more than eight weeks before they fell off (Wilson et al. 1997). Our limited manpower for this extensive, simultaneous study at the different sites also made it impossible for us to monitor attendance patterns of birds without devices to examine for potential device effects. Although such a comparison would have been preferable, it would have necessitated daily checks, at least, through the whole of the incubation period.

\section{Foraging areas}

The location of 47 Magellanic Penguins could be determined for the incubation periods, 10 birds from the 1994 period and 37 from the 1996 period (Table 1). The birds foraged at distances of up to $450 \mathrm{~km}$ from their home colonies (Fig. 2), with foraging sites being identified either by a depth use that regularly exceeded $10 \mathrm{~m}$ (all devices except global location sensors) or by substantially reduced bird displacement (global location sensing devices). However, penguins from San Julian and Punta Loberia in the middle of the distributional range considered here traveled significantly farther (Fig. 3) than penguins from any of the other colonies ( $t$ test on means from colonies derived from means of individual birds to ensure no pseudoreplication and subjected to the Kolmogoroff-Smirnof test to ascertain normality and $F$ test for equality in variances; all derived $P<0.05$ ). The birds from New Island, Cabo Virgenes, and San Lorenzo all tended to utilize areas in roughly the same geographical latitude as their colony, moving west, east, and east, respectively. In contrast, penguins from San Julian and Punta Loberia tended to move south and north, respectively (Fig. 2). This brought San Julian birds to within the foraging area of the birds from Cabo Virgenes, and Punta Loberia birds into the foraging area of the birds from San Lorenzo 


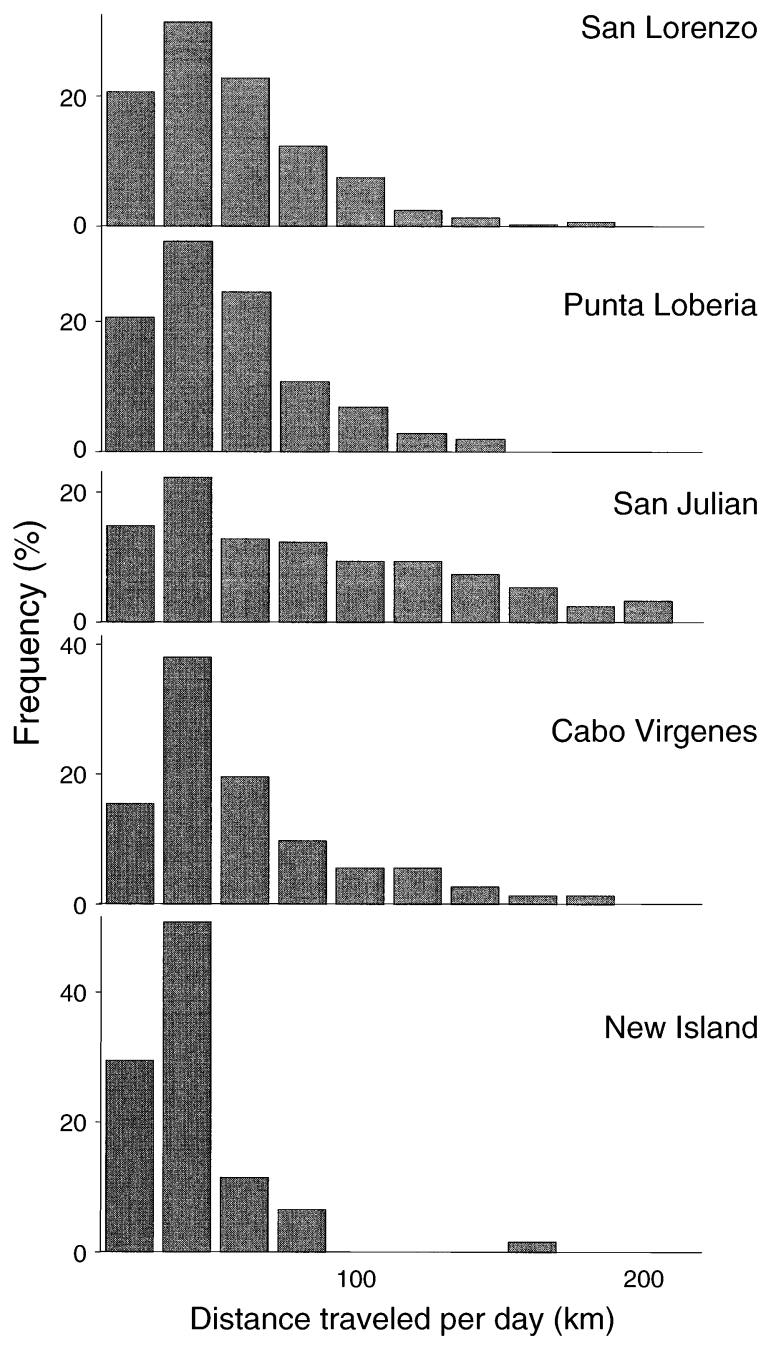

FIG. 4. Frequency distribution of distance traveled per day by Magellanic Penguins from five different colonies during foraging trips conducted during the incubation period.

(Fig. 2). A notable exception to the pattern was a single bird from Punta Loberia that traveled rapidly south after leaving the colony and was almost within the foraging area of penguins from San Julian before the device stopped recording (Fig. 2). As a result we were unable to determine the ultimate destination of this individual.

The foraging areas of the birds from the different colonies were the primary determinant for the frequency distribution of the distances that the birds spent away from their breeding colonies. It was notable that penguins breeding in the two most southerly colonies foraged close by, spending $>50 \%$ of their time at sea within $70 \mathrm{~km}$ of the breeding site and over $90 \%$ of their time within $175 \mathrm{~km}$ (Fig. 2). Birds in the far north at San Lorenzo traveled slightly farther, spending $50 \%$ of their at sea time within $100 \mathrm{~km}$ and $90 \%$ of their time within $200 \mathrm{~km}$ of the colony (Fig. 2). However, penguins from the two central colonies spent most time at greater distances from their colonies, with birds from
San Julian and Punta Loberia spending $50 \%$ of their time at sea within $150 \mathrm{~km}$ and $200 \mathrm{~km}$ of the colonies, respectively, and $90 \%$ of their time within $300 \mathrm{~km}$ and $375 \mathrm{~km}$ of the colonies, respectively (Fig. 2).

\section{Distances traveled per day}

The mean distance traveled per day ranged from 15.4 $\mathrm{km}(\mathrm{SD}=19.3)$ by birds from New Island to $54.3 \mathrm{~km}$ $(\mathrm{SD}=49.0)$ by birds from San Julian (Fig. 4). However, the distance traveled per day was not constant over the whole of the foraging period for birds from any colony. In keeping with rapid, highly directional movement away from, and towards, the colonies at the beginning and end of the foraging trips (associated with efficient displacement to and from the foraging grounds (see Wilson 2002), distances traveled on the first and last day were greater than distances traveled on other days (Fig. 5). This was, however, only significant for birds from the most northerly and southerly colonies (San Lorenzo, Cabo Virgenes, and New Island; Fig. 5), presumably, in part, because individuals from the central colonies spent many of the other days also traveling to and from the foraging sites, which increased the rates of movement during other portions of the foraging trip. In keeping with their greater overall distances moved during foraging trips, distances traveled on the first and last days by birds from San Julian were significantly higher than the equivalent distances traveled by birds from the colonies at the range extremes ( $U$ values of 40.5, 32.5, and 53.5; all $P<0.05$ ) for San Julian with Cabo Virgenes, New Island, and San Lorenzo, respectively). Sample size for the birds from Punta Loberia was too small for effective testing.

\section{Duration of foraging trips}

The time that birds spent at sea during foraging trips during the incubation period was highly variable both

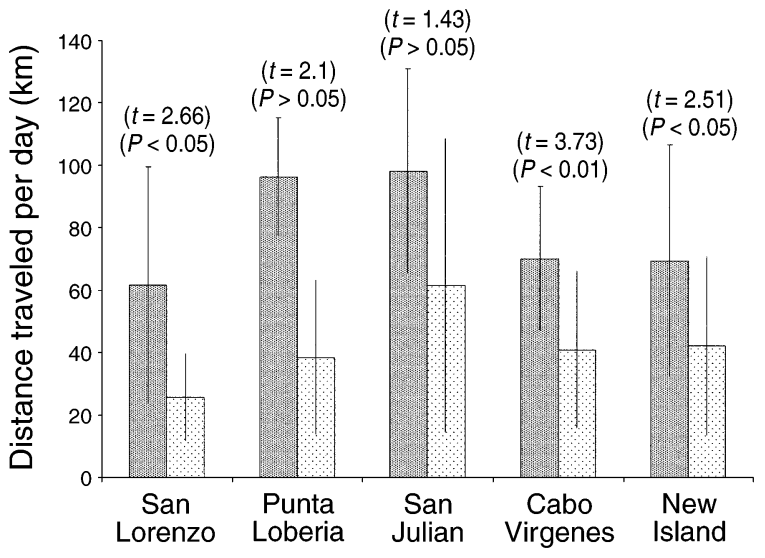

FIG. 5. Distances traveled on the first and last day (gray bars) compared to the distances traveled on other days (dotted bars) for Magellanic Penguins from five different colonies during foraging trips conducted during the incubation period. Values show means \pm SD for each colony where each value used for that mean is derived from all trips made by any individual bird. The number of individuals for each group is given in Table 1. 


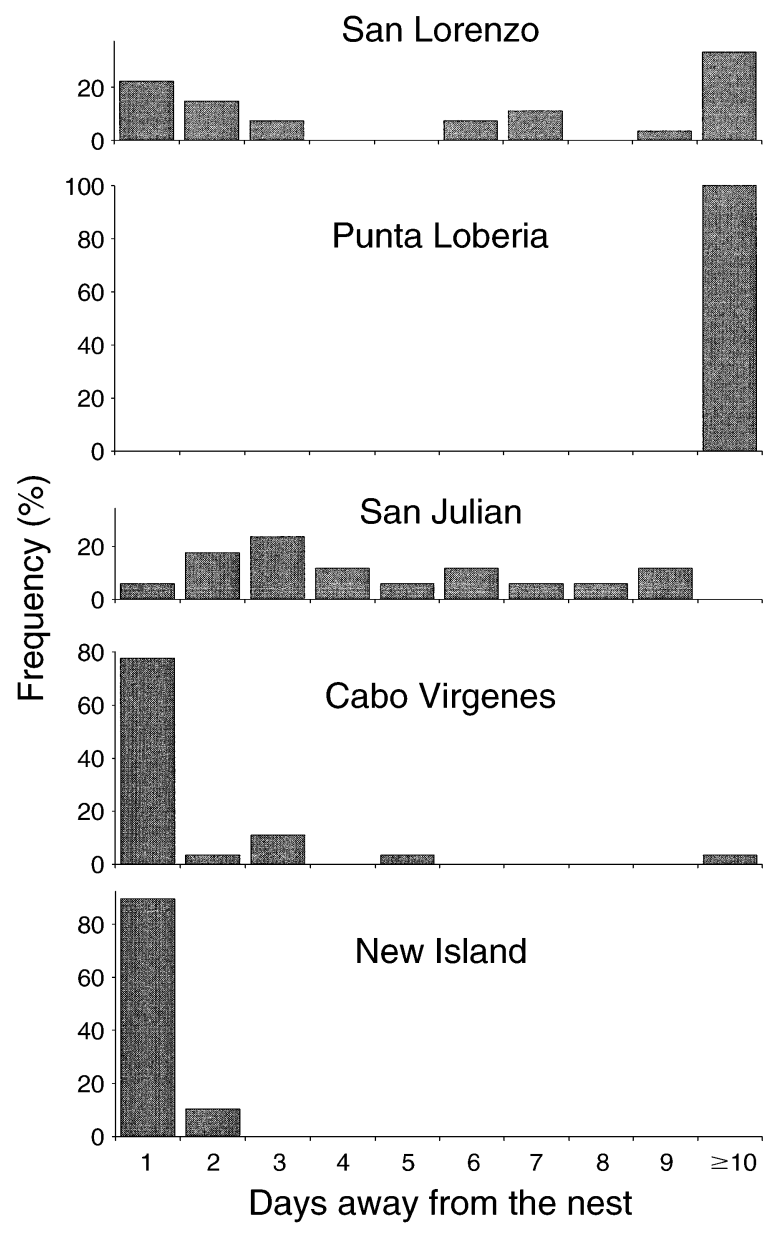

FIG. 6. Length of trips to sea made by Magellanic Penguins during the incubation period during October and November 1994 and 1996 as a function of colony location (see Fig. 1).

within and between colonies, with frequency distributions being significantly different among all colonies $\left(\chi^{2}\right.$; $P<0.05)$ except between New Island and Cabo Virgenes $\left(\chi^{2} ; P>0.05\right.$ : Fig. 6$)$. The length of time that birds were actually at sea varied between about three minutes and 23 days. It is highly unlikely that Magellanic Penguins foraged during the shorter periods at sea and closer inspection of the behavior exhibited by the birds during such periods indicated that dives were short (generally $<1 \mathrm{~min}$ ), shallow $(<10 \mathrm{~m})$, occurred relatively infrequently, and were irregular. Birds assumed to be foraging, however, dived continuously and relatively deeply (generally $>10 \mathrm{~m}$ for at least $20 \%$ of all dives) during well-defined dive bouts (sensu, Kooyman 1989). On the basis of consideration of the behavior exhibited by birds at sea we were able to eliminate periods when birds went to sea to forage and when they only went to bathe, drink, and preen. If the time at sea data are reconsidered on this basis, the longest foraging trips occurred in birds from San Lorenzo and from Punta Loberia (medians of 12 and 14 days, respectively) and the shortest trips from Cabo Virgenes (median 1 day).
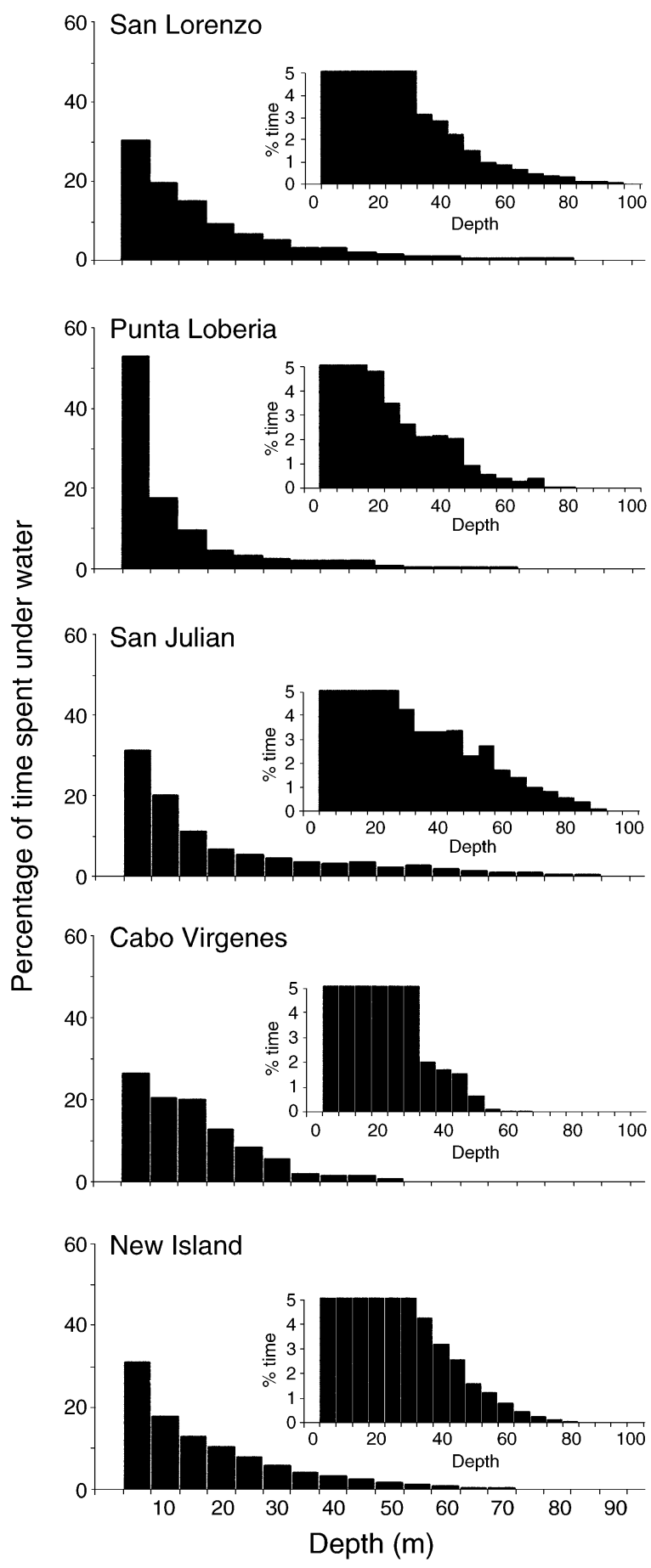

FIG. 7. Percentage of time spent underwater at various depths for Magellanic Penguins from five different colonies during foraging trips conducted during the incubation period (Table 1). The smaller graphs inserted show the same data with a different y scaling to emphasize inter-colony differences at greater depths.

\section{Foraging depths}

Depth use during the incubation period could be determined for a total of 33 Magellanic Penguins for the 1996 season. The birds dived up to maximum depths 

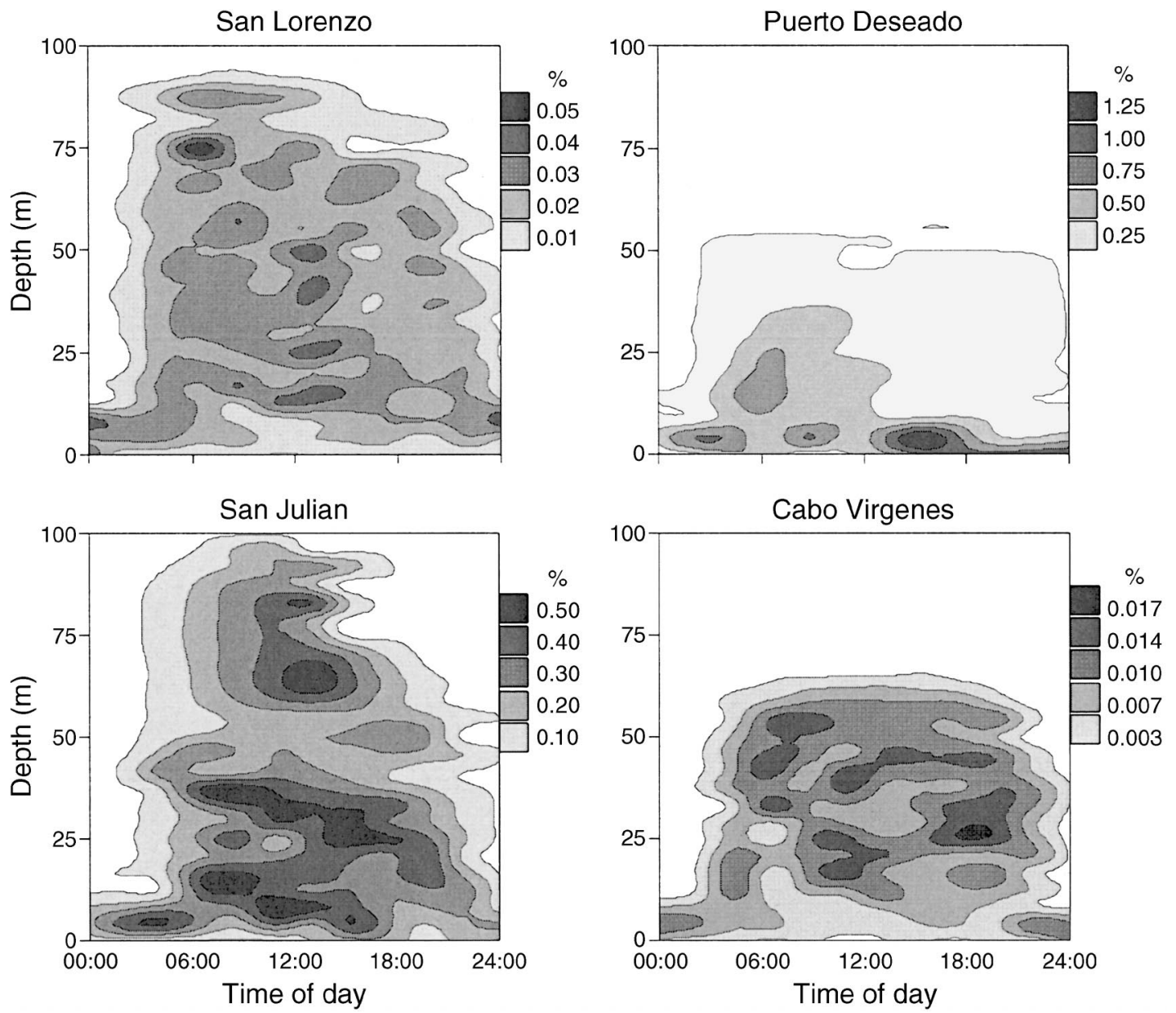

FIG. 8. Topographic plot (gridded according to the Kriging procedure using Surfer, Golden Software) of the percentage of time spent at depth during the bottom phase of dives for Magellanic Penguins from four different colonies foraging during the chick-rearing phase.

of $\sim 100 \mathrm{~m}$ during the incubation season although birds from all colonies spent more time closer to the surface (Fig. 7). This arises principally because birds must always travel back and forth between the surface and the point of maximum depth to get to the foraging zones (Wilson et al. 1991). This simple, absolute time-based analysis shows that penguins from Cabo Virgenes spent more time closer to the surface (95\% of all time spent underwater was at depths shallower than $35 \mathrm{~m}$ ) than individuals from any of the other colonies (all others had $95 \%$ of all time spent underwater at depths in excess of $45 \mathrm{~m}$ ). However, if the confounding effects of transit between the preferred foraging depth and the surface are eliminated by only considering the bottom phase of dives (see Appendix C), the picture changes substantially (Fig. 8). This process could only be carried out systematically for the 41 birds with devices that were rearing chicks since the high recording frequencies necessary for identification of the bottom phases (see Wilson et al. 1995b) could only be used for birds wearing devices for short periods. Data in Walker and Boersma (2003) indicate, however, that substantial differences in diving behavior between birds during the incubation and chick-rearing stages are not expected. Here, it became apparent that no bird from any colony dived deeply during the darkest period of the 24-h cycle (Fig. 8), and there was a general increase in the mean depths exploited during the day. Intercolony differences were substantial, with penguins from San Lorenzo and San Julian spending the most time in the deepest waters (up to $100 \mathrm{~m}$ ) while no birds from Cabo Virgenes exceeded $60 \mathrm{~m}$ and none from Puerto Deseado exceeded $50 \mathrm{~m}$ in depth (Fig. 8).

Consideration of the actual time spent in the various phases of the dive (i.e., descent, bottom phase, and ascent) showed broadly similar patterns for birds from all colonies, with descent and ascent durations increasing approximately linearly with increasing maximum dive depth, and bottom duration increasing up to depths of $\sim 20 \mathrm{~m}$ but decreasing steadily after that (Fig. 9). 

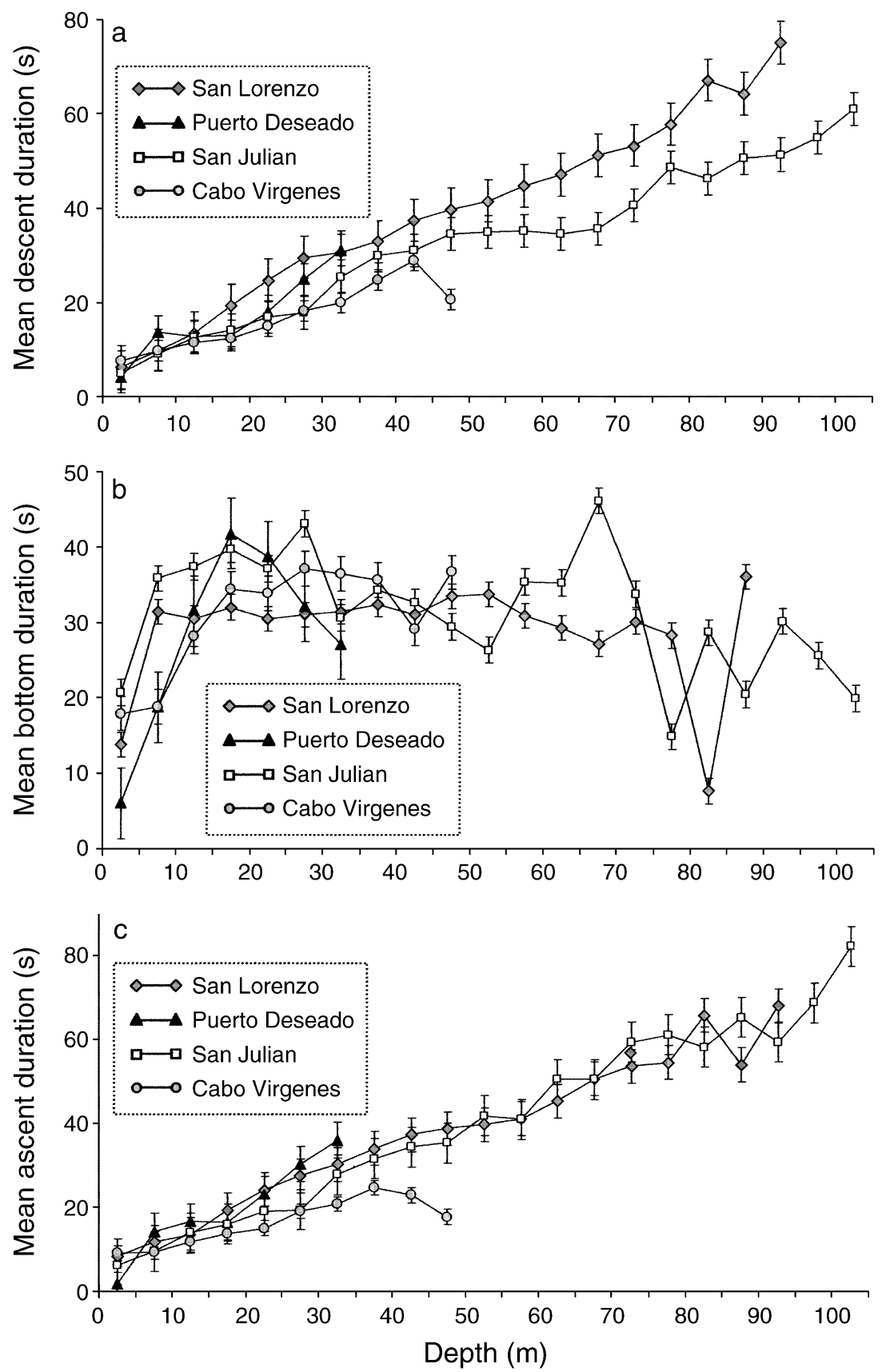

FIG. 9. Relationship between (a) descent duration, (b) bottom duration, and (c) ascent duration and depth during dives for Magellanic Penguins from four different mainland Argentinean colonies. Data are presented as means \pm SD for 5-m classes.

\section{Diet}

Although a total of 90 penguins had their stomachs flushed during the October 1996 incubation period, only $32(35 \%)$ of the birds had identifiable stomach contents. Fifty-eight birds returned with only indigestible material, which is not further analyzed here due to the biases that such work entails (Furness et al. 1984). The high incidence of birds with empty stom- achs was the main reason why it was decided to limit sampling to only a few birds per colony rather than persisting to increase sample size. At this time diet was very distinct according to area. Birds in the two most northerly colonies at San Lorenzo and Punta Loberia fed almost exclusively on anchovies, this making up more than $95 \%$ of all prey items taken. Birds in San Julian took $50 \%$ silverside and $50 \%$ squid, by number, 
TABLE 2. Importance of prey species (\%) by number for Magellanic Penguins breeding at different sites down the Argentinean coast (October 1996).

\begin{tabular}{lcccc}
\hline \hline \multicolumn{1}{c}{ Prey species } & $\begin{array}{c}\text { Cabo } \\
\text { Virgenes }\end{array}$ & $\begin{array}{c}\text { San } \\
\text { Julian }\end{array}$ & $\begin{array}{c}\text { Punta } \\
\text { Loberia }\end{array}$ & $\begin{array}{c}\text { San } \\
\text { Lorenzo }\end{array}$ \\
\hline Engraulis anchoita & 0 & 0 & 97 & 100 \\
Sprattus fuegensis & 99 & 0 & 0 & 0 \\
Myxinus spp. & 1 & 0 & 0 & 0 \\
Austroatherina spp. & 0 & 50 & 1 & 0 \\
Loligo & 0 & 50 & 1 & 0 \\
Odontestes spp. & 0 & 0 & 1 & 0 \\
Total no. samples & 20 & 30 & 20 & 20 \\
No. samples with prey & 9 & 5 & 9 & 9 \\
No. individual prey items & 570 & 36 & 79 & 136 \\
\hline
\end{tabular}

whereas penguins from Cabo Virgenes in the south took almost exclusively (99\%) sprats, although a few hagfish juveniles were also taken (Table 2).

All $60(100 \%)$ penguins flushed during the November/December 1997 chick-rearing period contained food. This is to be expected since the birds were likely to have been provisioning chicks at this time. As in October, penguins in the north of the range at San Lorenzo had fed primarily (90\%) on anchovy whereas birds in the south at Cabo Virgenes took almost exclusively sprats $(99 \%)$. The situation had changed at San Julian, however, with penguins feeding predominantly on sprats $(64 \%)$ at this time, although appreciable numbers of silverside (28\%) and some squid (8\%) were also taken (Table 3).

At all sites, the primary prey were relatively small. The sprats taken (all samples combined) had a mean length of $37.3 \mathrm{~mm}(\mathrm{SD}=3.1, N=276)$ and the anchovies (all samples combined) had a mean length of $112.3 \mathrm{~mm}(\mathrm{SD}=29.9, N=176)$. Squid varied greatly in size, with mantle length ranging from $11 \mathrm{~mm}$ to 135 $\mathrm{mm}$.

\section{Model output-derived site-specific prey availability and relationship to foraging parameters}

Our model to derive site-specific prey availability used linear relationships, and thus it is not surprising that for a given time spent in the foraging area, the putative rate of prey ingestion $(\Delta I)$ increases linearly with increasing distance to the foraging site (Fig. 10). Critical, however, and less inherently obvious, is the observation that for any particular distance to the foraging site, the putative rate of prey gain decreases in the manner approximating an exponential decay when graphed against the time in the foraging zone (Fig. 11). This stems from the biological necessity for the birds to expend energy to survive (even in the foraging zone) and as prey densities reduce, putative ingestion rates approach energy expenditure rates more closely, which necessitates investment of a disproportionately longer time to repay energy debts incurred during incubation. In other words, small changes in prey availability when prey are generally abundant make little difference to the amount of time that birds have to spend in the foraging area, but as prey abundance decreases to a lower critical value (corresponding to putative ingestion rates of $\sim 0.1 \mathrm{~kg} / \mathrm{h}$ in our example) the time necessarily spent in the foraging area increases disproportionately.

\section{DisCUSSION \\ Effect of devices}

Given that device-induced aberrant behavior has been demonstrated for penguins on numerous occasions (see e.g., Ropert-Coudert et al. 2000 and references therein), it is appropriate that we consider the issue here. Although the units that we deployed were shaped so as to minimize hydrodynamic drag, we equipped different birds with devices of various sizes and did not standardize device types for different colonies. This is important since increasing device crosssectional area results in reduced swimming speeds (Wilson et al. 1986) and increasing device volume appears to reduce the maximum depth reached (Wilson 1989). Fortunately, however, some of the largest devices were put on birds that dived the deepest at San Lorenzo so that this effect is not apparent in our data. Our premise is that devices had an effect on penguin swimming and diving performance to some extent in all cases (Wilson and Culik 1992, Culik et al. 1994a). However, overall, we consider the fact that our data suggest that only a single individual of the 92 equipped with devices actually stopped breeding (and the cause of this is also not certain) to be indicative of relatively little distress to the equipped birds.

\section{Intercolony variability in diet}

Magellanic Penguins are typical of other members of their genus in that they appear to specialize on feeding on pelagic school fish (for review see Williams 1995). They are reported to feed primarily on anchovy Engraulis ringens, sardine Sardinops sagex, sprat, and, to a lesser extent, squid Todarodes fillippovae in Chile (Venegas and Sielfeld 1981, Venegas and Almonacid 1994, Wilson et al. 1995a, Radl and Culik 1999), and the diet of Magellanic Penguins from the various col-

TABLE 3. Importance of prey species (\%) by number for Magellanic Penguins breeding at different sites down the Argentinean coast (November/December 1997).

\begin{tabular}{lccc}
\hline \hline \multicolumn{1}{c}{ Prey species } & $\begin{array}{c}\text { Cabo } \\
\text { Virgenes }\end{array}$ & $\begin{array}{c}\text { San } \\
\text { Julian }\end{array}$ & $\begin{array}{c}\text { San } \\
\text { Lorenzo }\end{array}$ \\
\hline Engraulis anchoita & 0 & 0 & 90 \\
Sprattus fuegensis & 99 & 64 & 0 \\
Loligo & 1 & 8 & 2 \\
Odontestes spp. & 0 & 28 & 0 \\
Scomberesox spp. & 0 & 0 & $<1$ \\
Agonopsis chiloensi & 0 & 0 & 7 \\
Total no. samples & 20 & 20 & 20 \\
No. samples with prey & 20 & 20 & 20 \\
No. individual prey items & 395 & 459 & 888 \\
\hline
\end{tabular}


Time in foraging zones (days)

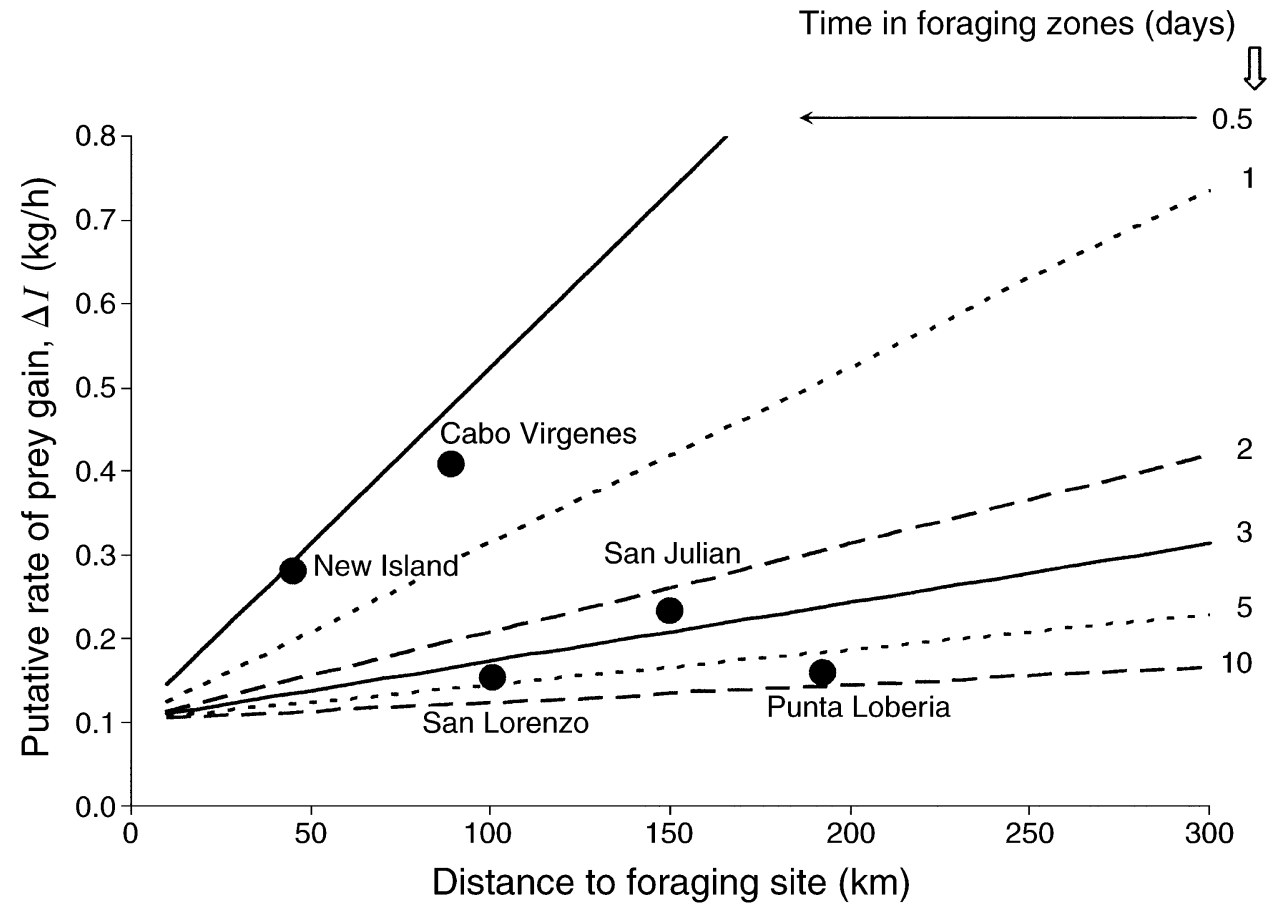

FIG. 10. Putative rate of prey gain as a function of distance between nesting area and foraging site for Magellanic Penguins spending varying amounts of time in the foraging zone according to the conditions set out in the model. It is assumed that during their foraging trips the penguins exactly balance energy expenditure during both incubation and foraging with energy gain. Values for energy expenditure according to activity (resting on land, resting in water, traveling underwater) are derived from the literature, as is the budget for time vs. activity for penguins in the foraging area. The speed of traveling Magellanic Penguins is derived from our data (see Fig. 5), as are the approximate limits for viable distances to the foraging site as well as times likely spent in the foraging zone. Total times allocated to traveling and foraging are varied within the model to show the necessary rate of ingestion for penguins in order to achieve a steady-state situation for energy. Black dots show the putative rates of prey gain for Magellanic Penguins on foraging trips from the different colonies. Here, values for the distance to the foraging site and the time actually spent in the foraging area are taken from data collected from our freeliving birds from the respective areas.

FIG. 11. Putative rate of prey encounter as a function of time spent in the foraging area by Magellanic Penguins foraging at variable distances from the nesting area (cf. Fig. 3). This is another representation of the data presented in Fig. 10 (conditions are identical; see legend for Fig. 10) to show how critical prey density is in determining the length of time necessary in the foraging zone if energy input is to be exactly balanced with output. Again, dots show the conditions (length of time in the foraging zone and distance to foraging site) experienced by the penguins from the different breeding sites.

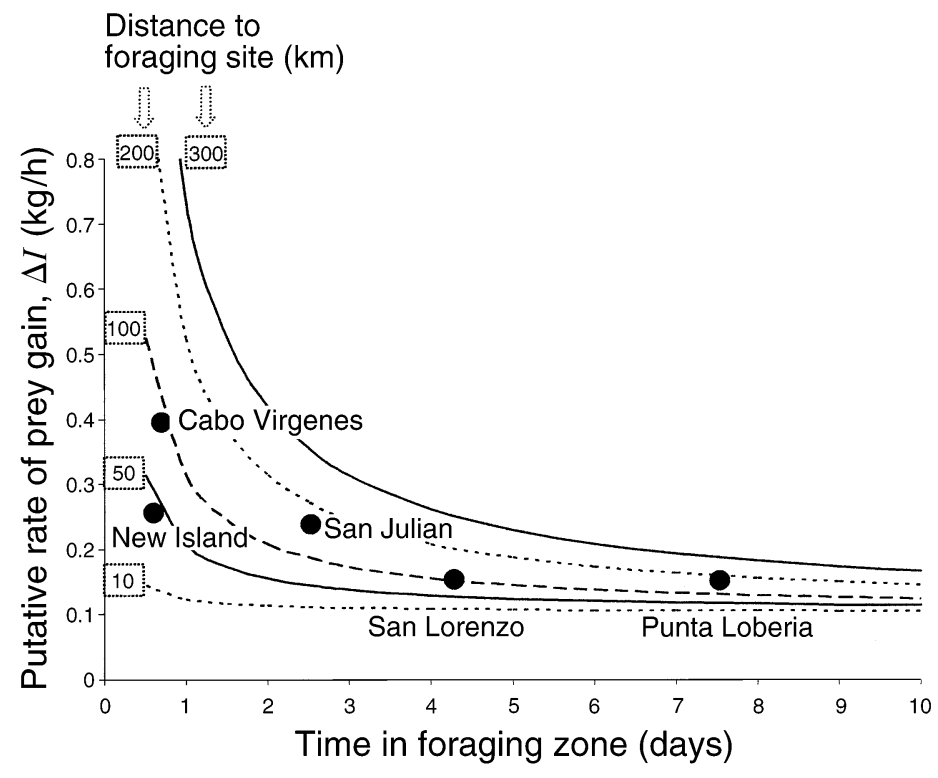


onies situated down the species latitudinal range in Argentina, as determined by our group, accords with that already published for similar, or proximate sites. We note here that Magellanic Penguin diet seems to be both site stable and year stable, with various authors reporting that these penguins are essentially monophagic at the extreme ends of the distributional range, consuming almost exclusively anchovy in the north (Gosztonyi 1984, Scolaro and Badano 1986, Frere et al. 1996, Scolaro et al. 1999) and large quantities of sprat in the south (Frere 1993, Frere et al. 1996, Scolaro et al. 1999, Forero et al. 2002; cf. Clausen and Pütz 2002). Thus far, this is to be expected for a species specializing on pelagic school fish and living in an area that is well within the distributional range of the two major fish species (Sánchez et al. 1995, Hansen et al. 2001). However, it is notable that prey species that constitute "incidental prey items" for birds living at the range extremes, become much more prevalent at colonies situated between these two extremes with squid becoming a particularly obvious dietary element (Frere et al. 1996, Scolaro et al. 1999). Thus, the diet of Magellanic Penguins at Puerto Deseado, virtually in the middle of the two range extremes, consists of only $15 \%$ sprats, $\sim 30 \%$ squid, and $55 \%$ other species including silverside, hake, and snook (Frere et al. 1996). This is hardly surprising. Although the distribution of anchovy is reported to extend down to $48^{\circ} \mathrm{S}$, species abundance drops markedly after $44^{\circ} \mathrm{S}$ (Hansen et al. 2001; data available online). ${ }^{7}$ The distribution of sprats extends up to about $47^{\circ} \mathrm{N}$, but abundance decreases substantially at latitudes lower than about $50^{\circ} \mathrm{N}$ and highest densities are recorded between $52^{\circ} \mathrm{S}$ and $54^{\circ}$ S (Sánchez et al. 1995). In any case, this distribution is not static. During the course of the austral summer, sprats are reported to extend their distribution northwards along the coast (Quintana and Yorio 1997, Cousseau and Perrotta 1998). This migration could explain the absence of this species in the Magellanic Penguin diet during our sampling in October but its appearance by December (cf. Tables 2 and 3) and its complete absence in the diet of penguins at Puerto Deseado until January (Frere et al. 1996). The dependence of Magellanic Penguins on species, particularly squid, other than those considered typical prey for its genus (such as Sardinops, Engraulis, Sprattus; see Williams 1995 and references therein) in the center of its latitudinal range may partially explain the relatively lower abundance of penguins nesting in this area (Fig. 1). Heath and Randall (1985) noted that chicks of the very similar African Penguin Spheniscus demersus had a lower metabolic efficiency, grew markedly slower, and achieved lower fledging weights when fed on squid than on anchovy, and Wilson et al. (1985) reported how adult African Penguins apparently have problems digesting squid and take approximately four times longer to evac-

\footnotetext{
${ }^{7}\langle$ http://www.fishbase.org $\rangle$
}

uate it from the stomach than for anchovy, despite the fact that squid have a lower energy density (Heath and Randall 1985).

\section{Intercolony variability in depth utilization}

A number of studies have examined the diving behavior and depth utilization of Magellanic Penguins (Scolaro and Suburo 1991, Wilson et al. 1995a, Peters et al. 1998, Radl and Culik 1999, Walker and Boersma 2003). The general picture to emerge is that this bird's diving capabilities conform to those expected for a Sphenisciform of its size (Prince and Harris 1988, Burger 1991, Wilson 1995, Boyd and Croxall 1996, Schreer and Kovacs 1997, Watanuki and Burger 1999), with the proviso that bottom topography, particularly over the Patagonian shelf, serves as an absolute limit to its performance (Walker and Boersma 2003; cf. Wilson 1985). Our data on depth utilization generally accord with those documented to date (Fig. 7) and also underline the extent to which maximum dive depth is determined by light (Fig. 8), something that has been observed in this species (Peters et al. 1998, Walker and Boersma 2003) and many others (see Cannell and Cullen 1998 and references therein). Superficially, the time spent at depth does not seem to differ radically between birds from different colonies (Fig. 7); and again, this would appear to conform with data presented by other authors where attempts have been made to equate depth use with the vertical distribution of prey (Radl and Culik 1999, Walker and Boersma 2003). However, to date, these treatises have tended to ignore the fact that penguin time spent underwater may be broadly divided into that spent traveling horizontally close to the surface (Wilson 1995), that spent searching for prey in the vertical dimension, and that spent searching for, and also finding, prey in the horizontal dimension at depth (cf. Simeone and Wilson 2003). The necessity of the distinction is not trivial, primarily because any bird that takes time to descend to a certain depth must invest a similar amount of time to return to the surface (e.g., Peters et al. 1998), whether it is beneficial for that animal to do so with respect to prey encounter probabilities or not. This means that cognizance of total time spent at depth (Fig. 7) and even, to an extent, the frequency distribution of maximum depths does not necessarily help determine the depths considered most profitable by the birds. Consideration of the depth distribution of bottom times goes a long way to solving this problem, first because most prey ingested by Magellanic Penguins are taken during extended bottom phases (see Simeone and Wilson 2003) and second because, even in the absence of prey ingestion, these bottom phases are extended by bird choice rather than being a necessity for survival. As such we would expect there to be strong selection pressure for penguins to concentrate their horizontal search for prey at depths where they are most likely to occur (Wilson et al. 1996). 
Bearing this in mind, there appears to be considerable variation in the depth distribution of the Magellanic Penguin bottom times according to colony location (Fig. 8). Aside from visual limitations restricting penguin depth use (Wilson et al. 1993), the diel vertical migratory behavior of anchovies, with fish being close to the surface at night and moving down the water column during the day (Gudmundsson and Gamberale 1972, Hansen and Madirolas 1996, Hansen et al. 2001), may explain why it was that penguins from San Lorenzo showed the depth distribution they did. Perplexingly, however, birds spending appreciable amounts of time at depths in excess of $70 \mathrm{~m}$ (Fig. 8), would appear to be diving deeper than the depth distribution of anchovies would appear to necessitate (Hansen et al. 2001). Sprat distribution within the water column also depends on time of day. During the night most of the fish are concentrated within $5 \mathrm{~m}$ of the surface but they descend the water column at dawn and, in the southern Patagonian Shelf area at least, spend the day within a few meters of the bottom (Sánchez et al. 1995) so depth use over time by penguins from San Julian and Cabo Virgenes, which certainly accords with this, is presumably dictated by bottom topography (Fig. 8). The substantial increase in use of greater depths by the San Julian birds over that of the Cabo Virgenes individuals may be due to the sprats of the region being located at greater water depths although, with the increased percentage of squid in the diet, we cannot rule out that it is not related to squid exploitation. Depth use by birds from Puerto Deseado was remarkably limited with almost all extended bottom time spent at depths $<20 \mathrm{~m}$ (Fig. 8). Definitive data on the depth distribution of the many prey species taken by the penguin at this locality are lacking but we can only assume that most prey types are located close to the surface (Cousseau and Perrotta 1998) so that deep dives are not profitable.

In fact, one might expect deep dives to be generally energetically unfavorable anyway due to a putative negative relationship between bottom duration and depth as a result of the increasing costs of transit in deep dives using limited oxygen reserves. This assumes, however, that penguins dive with a constant amount of body oxygen irrespective of depth. Recent work has shown that this is not the case for Magellanic Penguins (Wilson and Zimmer 2004; cf. Wilson and Quintana 2004), which might partially explain the perplexing way bottom duration changes with increasing dive depth (Fig. 9b). Rather, birds inhale so that the effects of air-mediated upthrust are modulated to result in minimal upthrust at the chosen foraging (bottom) depth because this leads to minimized energy expenditure (Wilson and Zimmer 2004). Actual time spent at any depth, and ultimately total time underwater, depends on body oxygen stores, the amount of air stored in the birds lungs and air-sacs, the angles and speeds of descent and ascent, and the speeds and accelerations used during the bottom phase (Wilson et al. 2002, Wil- son and Zimmer 2004). Speed is a particularly important and confounding element in this since energy expenditure, and thus oxygen use, increases as a cubed function of speed (Culik et al. 1994b, Luna-Jorquera and Culik 2000) so that extensive pursuit of fast prey is predicted to shorten bottom duration radically (Wilson et al. 2002). The pursuit speeds of Magellanic Penguins taking various prey types has not yet been elucidated so variable bottom durations according to location (Fig. 9b) must be treated accordingly. The optimal decision as to the depths to which Magellanic Penguins should dedicate most time is thus highly complex but should also be cognizant of options open to the prey to minimize capture such as diel vertical migration, unpredictable scattering throughout the water column, and feeding at the surface at night where the high phytoplankton concentrations can be exploited but where visual predators, such as penguins, cannot effectively operate (for discussion see Wilson et al. 1993).

\section{Intercolony variability in selection of foraging areas}

The substantial intercolony variability in time spent at sea, distance traveled to the foraging grounds, and time spent in the foraging grounds would indicate that birds from the different sites experience very different local conditions in prey availability and distribution. Certainly, the prey species recovered from the birds as they returned to their colonies from incubation trip forays would indicate this, although only prey caught relatively close to the colony are unlikely to have been digested during this phase (Wilson et al. 1985; cf. Gauthier-Clerc et al. 2000). During the incubation period, birds from mainland colonies visited two major sites; one was adjacent to, and slightly south of, Cabo Virgenes and the other was to the west of Peninsula Valdés. Sprat biomass densities $\left(>800 \mathrm{~kg} / \mathrm{km}^{2}\right)$ are highest immediately to the south of the Magellan Strait (Sánchez et al. 1995) and large amounts of juvenile sprat collected during extensive surveys (with juvenile production for the area being estimated at $1.3 \times 10^{9}$ individuals) indicate a major nursery, with major spawning peaks in late December and mid January (Sánchez et al. 1995). This is reason enough for birds to concentrate foraging effort at this site. Similarly, extensive frontal systems around Peninsula Valdés (Carreto et al. 1986, Martos and Sánchez 1997), based on a thermohaline front and two tidal fronts, are important in defining the spawning areas of the Patagonian stock of the Argentine anchovy (Sánchez and Deciechomski 1995, Martos and Sánchez 1997).

The critical relationship between prey availability and time spent in the foraging area (Figs. 10, 11) highlights the importance of making the correct decision regarding where to forage for central place foragers (see Lewison and Carter 2004 and references therein) and there are good, obvious reasons for birds to select zones of highest prey densities. Absolute highest prey 
densities are not the only consideration, however, and birds should choose to visit the area for which the combination of time and costs allocated to both travel and foraging minimize time away from the nest, because more extended periods away will tax the body reserves of the incubating partner and ultimately increase the risk of nest desertion. Apparently, prey densities in the south are so much higher than those in the north that foraging trips can be extremely short (Fig. 11). Such a strategy involves less risk of desertion by the partner at the nest because there is little danger of stored energy reserves becoming critically depleted (cf. Davis and Miller 1992, Gauthier-Clerc et al. 2001, Robin et al. 2001).

This scenario does not, however, help explain how birds might decide which direction to take when leaving the colony although the consequences for making an inappropriate decision are clear. The tracks of birds leaving the various colonies indicate that different strategies are adopted by different colonies. Birds at the mainland colonies in the south travel south, east, or southeast, birds at New Island tend to travel west, while birds in the north, with the exception of one notable individual that traveled south, tended to travel north, east, or northeast. There are four major options that may be instrumental in determining the direction birds leaving to forage might take.

1) Birds might follow odor plumes to the source of prey. This has been shown to occur in Procellariiformes (Nevitt et al. 1995, Nevitt and Haberman 2003) and may be a major element in general foraging strategies. Culik et al. (2000) document Humboldt Penguins apparently following odor plumes although sample size in their study was five birds, only two of which swam to areas of enhanced productivity. For the case of the Magellanic Penguins in our study area, wind direction, being predominantly blown from the west for all sites (Glorioso 2000), is not appropriate for the tracks shown (Fig. 2). In addition, in order to be able to discern gradients, and therefore home in on a food source, animals using olfaction must displace themselves over this gradient to an extent that allows their sensory capacities to register a difference over a given scale of movement (Wolf and Wehner 2000). The greater the distance between the source and the animal, the less well defined will be the gradient and the greater the sinuous movement of the animal must be to home in on that source (Kerguelen and Carde 1997). We note that penguins, with their low traveling speed (Wilson 1985) compared to Procellariiformes (e.g., Waugh and Weimerskirch 2003), are poorly adapted for such a searching strategy for food sources many 10 s of kilometers distant. Finally, the highly directional swimming behavior of penguins leaving their colonies in this study and elsewhere (Wilson 2002) certainly does not mirror an olfactory-based search strategy (cf. Mafraneto and Carde 1994 and references therein), al- though once in the foraging area where prey are close this might change (Wilson 2002).

2) There may be a genetic basis to the movement of birds from different colonies during the incubation periods. Given that Magellanic Penguins, like their congeners, specialize in hunting pelagic school fish (see references in Williams [1995] for an overview of the dietary habits of the genus), the areas with the highest food densities at that time of the year appear to the south of $50^{\circ} \mathrm{S}$ latitude, where the sprat is prevalent, and to the north of $43^{\circ} \mathrm{S}$ latitude, where the anchovy dominates. We note that this ties in with our dietary samples. Over a scale of 10 s of kilometers the prey distribution is more or less stable from year to year (Sánchez and Deciechomski 1995, Sánchez et al. 1995, Martos and Sánchez 1997) so, if there were little interchange between colonies, there would be strong selection pressure for birds to travel appropriately. However, recent work has shown appreciable interchange between colonies, at least in the north, so genetic differences in foraging movements seem unlikely.

3) Birds may learn and remember where they have to travel in order to forage most successfully (Irons 1998). This has been suggested to be the case in Common Murres Uria aalge exploiting spatially predictable prey for a range of up to $100 \mathrm{~km}$ (Davoren et al. 2003).

4) Finally, and this option is not mutually exclusive of the explanations above, birds may adopt the appropriate strategy from conspecifics. Such behavior has been alluded to, for example, in auks in Canada (Burger 1997, Davoren et al. 2003) and constitutes a major element in the information centre concept (see Wright et al. 2003 and references therein). The ability to learn from conspecifics will tend to result in local populations doing the right thing and will be enhanced if the prey population distribution is spatially invariant over extended time periods.

The differences in putative prey ingestion rates calculated from our model (Figs. 10,11), which are likely to be linked to prey abundance, for the two major prey types (anchovy and sprat; Tables 2, 3) in the two major regions considered important for Magellanic Penguins feeding during the incubation period (Fig. 2) can be coupled with what is known about the distributions of prey to derive the projected length of the incubation foraging trip as a function of colony location for the area of Patagonia considered by us (Fig. 12). In this, cognizance should be taken of the fact that we do not have specific measures of prey densities over the $\mathrm{Pa}$ tagonian Shelf for 1996 when most of the birds were equipped and prey variance in distribution may be a confounding factor in this (see footnote 7). The model predicts how the length of the foraging trip increases with increasing distances from both Peninsula Valdés and Cabo Virgenes, assuming that birds nesting in between these sites always travel to one foraging area irrespective of how far away it is. However, the two "projected length of foraging trip" lines corresponding 


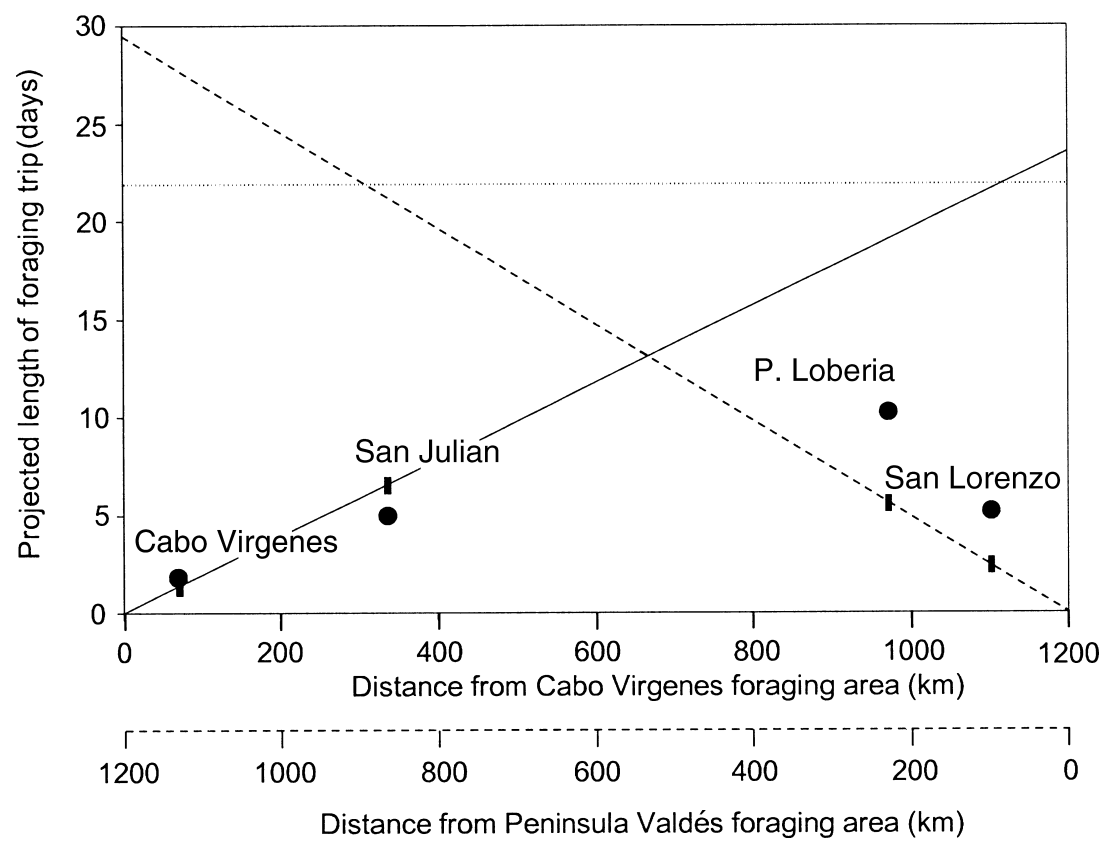

FIG. 12. Projected length of Magellanic Penguin foraging trips during the incubation for birds breeding at different sites located between Cabo Virgenes and Peninsula Valdés (cf. Fig. 2). Here, however, it is assumed that the birds always either visit the foraging grounds in the north (dashed line) or the south (continuous line), irrespective of the location of their breeding colony. For this, birds must travel the distance between their breeding and foraging site at speeds defined by our data loggers, expending energy at a rate defined by values derived from the literature (see legend for Fig. 10). This approach uses parameters defined in the text for Fig. 10 and assumes that rates of prey ingestion for feeding are $405 \mathrm{~g} / \mathrm{h}$ and $159 \mathrm{~g} / \mathrm{h}$ for birds feeding in the Cabo Virgenes and Peninsula Valdés areas, respectively (these values being derived from Fig. 10 according to putative rates of prey ingestion calculated for the respective areas). The dotted horizontal line highlights foraging trip lengths of 22 days. If the trip is longer, the incubating partner is highly likely to desert the nest (Wilson et al. 1995c, Walker and Boersma 2003). The short vertical bars show the location of four mainland Argentinean Magellanic Penguin colonies, and the black dots show the actual mean foraging trip length for those sites according to our logger-derived data.

to birds exploiting the northern and southern foraging zones cross at a distance of $\sim 670 \mathrm{~km}$ from the Cabo Virgenes site and $\sim 530 \mathrm{~km}$ from the Peninsula Valdés site (which approximately corresponds to the position of Puerto Deseado), indicating that birds nesting at this position will be equally well served irrespective of whether they move north or south to forage. Naturally, those birds nesting closest to the foraging grounds (and moving to the nearest foraging sites) have the shortest foraging trip lengths, something that must be considered advantageous due to less chance of nest desertion by the partner incubating the eggs, and which may partially explain why the penguin colonies in the north and the south of the distributional range, close to the foraging areas, tend to be larger (Fig. 1).

The distribution of Magellanic Penguin nesting colonies over the Patagonian Shelf has been rather dynamic in the northern regions over the past three decades. In their revision of the Magellanic Penguin colonies in Argentina, Boswell and MacIvor (1974) made no mention of this species being present at Peninsula Valdés, although since then a number of authors have reported substantial range extensions into and beyond this area (Daciuk 1976, Scolaro and Kovaks 1978, Pagnoni et al. 1993) with rapid increases in numbers at these new colonies (Perkins 1984, Carribero et al. 1995, Yorio et al. 1998, Yudego et al. 2000). This range expansion has been discussed by various authors (e.g., Boersma et al. 1990, Carribero et al. 1995), the change apparently being due to immigration (Scolaro et al. 1980, Carribero et al. 1995) rather than site-specific increases due to reproduction (Scolaro 1987, 1990). Reasons for this are unclear. However, a major frontal system ranging around Peninsula Valdés and associated with enhanced productivity (Carreto et al. 1986) may make the area particularly favorable for anchovies and may indeed be a major component helping explain anchovy distribution. Penguins in the area presumably benefit from this (Wilson et al. 1995c), which may explain why birds from both Punta Loberia and San Lorenzo tended to congregate in this area during incubation foraging trips (Fig. 2; cf. Wilson et al. 1995c). Interestingly, concomitant with the range expansion in the north, colonies immediately to the south of Peninsula Valdés appear to be declining in numbers. Punta Tombo $\left(44^{\circ} 02^{\prime} \mathrm{S}, 65^{\circ} 11^{\prime} \mathrm{W}\right)$ probably included between 400000 and 500000 nests during the 1970s (Boswell and MacIvor 1974, Daciuk 1976, Gochfeld 1980, Scolaro and Arias de Reyna 1984) but had dropped to less than half that by the end of the 1980 s 
(Boersma et al. 1990, Boersma and Stokes 1995, Yorio et al. 1998; see also Boersma 1997), while other colonies in the area, although less large, dropped by similar degrees (Badano et al. 1982, Scolaro et al. 1984, Capurro et al. 1988, Yorio et al. 1998).

Penguins of the genus Spheniscus are highly specialized to feed on pelagic school fish (Wilson and Wilson 1990) and indeed they only seem to occur in any appreciable numbers where prey of this type are available (see Williams [1995] for data relating to this). Boersma et al. (1990) report on the overall northward movement of the breeding distribution of Magellanic Penguins, although the time scale over which this has occurred is vague due to lack of precise data, and they speculate that this might be due to changes in the location and abundance of their food. They specifically suggest that one reason could be the harvesting of pinnipeds in the 1940s and 1950s that could have had an effect on both food supplies and predation pressure. We suggest that the northward population expansion of the Magellanic Penguin was coupled with a necessary switch from one prey type (sprat) to another (anchovy) and a corresponding change in foraging tactics, although we cannot say what factors might have catalyzed the movement. Certainly, colonies in the south of the distributional range were densely populated as early as the 1930s (Murphy 1936) and there is apparently substantial conspecific food competition in larger colonies (Forero et al. 2002) that might have facilitated emigration. In addition, although the southern limit of anchovy is normally of the order of $4^{\circ}$ of latitude north of the northern limit of the sprat (Sánchez et al. 1995, Hansen et al. 2001), there are times when distributions may overlap (Cousseau and Perrotta 1998) so the jump to the northern regions might have been enhanced by this. Overall though, colonies located increasingly farther north of Cabo Virgenes will primarily have been composed of birds that had to travel farther to get to an area where the rate of prey gain could cater for overall energy expenditure within a time that allowed the partner to continue incubation without an appreciable risk of starvation leading to desertion (see e.g., Robin et al. 2001; Fig. 12). Data in the literature suggest that incubating Magellanic Penguins will desert their nest if they are not relieved by their partners within about 22 days (Wilson et al. 1995c, Walker and Boersma 2003) so that birds breeding at Punta Loberia can still theoretically travel to the southern foraging area and continue to breed (Fig. 12), although this would be at the limit of their capacities. Interestingly, one individual from Punta Loberia appeared to be doing just that in our study (Fig. 2) although an instrument malfunction prevented us following the animal for the full duration of its foraging trip. However, birds from this site moving to the northern foraging site (which all other five individuals in our study did) reduce the minimum necessary foraging trip length to only about six days, even though prey capture rates in the northern foraging area are predicted to be less than half those in the south (Fig. 11). Thus, the appropriate strategy for birds nesting distant from two spatially distinct foraging areas depends, ultimately, on the relative rate of energy gain in each of the areas and their distances to the nesting site. As the population moves northward the monostable directionality in movement (to the south) is likely to be replaced by a metastable strategy where birds move either south or north, and finally, still farther north to a monostable strategy where all birds always move north to forage. In this respect it would be interesting to examine the movements of penguins nesting at Puerto Deseado, which lies at the point where a metastable strategy might be expected.

Considerations of penguin foraging strategies during the incubation period are not the only elements that will determine colony breeding success. Aside from other elements (such as weather and predation; see Frere 1993), appropriate prey must be available close to the colony during the chick-rearing period because the time available for foraging is very limited. In this respect, sprat distribution is reported to expand to the north over the austral summer, with particularly high concentrations adjacent to the coast (Sanchez and Deciechomski 1995, Cousseau and Perrotta 1998). Similarly, anchovies are reported to move southwards almost to the latitudes of Puerto Deseado (Hansen and Madirolas 1996, Cousseau and Perrotta 1998, Hansen et al. 2001) during the course of the penguin breeding season, helping penguins nesting in this area to have an appropriate supply of food for the brood. Our stomach samples taken from the various colonies attest that this is indeed the case (Table 3).

The different prey types result in very different diving behavior for the penguins from the different colonies (Fig. 8). Aside from demonstrating the dangers of typifying the foraging behavior of a particular species based on results stemming from individuals from a single site (Tremblay 2001; cf. Walker and Boersma 2003), it would be interesting to know whether this foraging behavior develops during the course of individual foraging trips as a result of the prey distribution or whether the birds initiate their search with a particular strategy that favors a particular prey type from the outset. The movements of penguins during the incubation period are analogous to the latter situation. Work-using concepts such as "search images" (e.g., Blough 2002) and "switching" (Wanink and Zwarts 2001) indicate that a specific prey-searching strategy is possible and would confer a selective advantage on individuals doing it. Careful assessment of the foraging behavior using remote-sensing systems should shed some light on this in the future.

The case study here shows how a predator population reacts to different prey distributions associated with different regions, with the example being particularly interesting because of the vast differences in potential foraging ranges that the different breeding phases en- 
gender. It demonstrates enormous flexibility in foraging strategy over the distributional range and implies that such flexibility is a critical factor allowing species to expand their ranges. In a world where species are being increasingly threatened by man (Boersma et al. 1990, Boersma and Stokes 1995, Gandini et al. 1996) it would appear that such flexibility might help survival in species that might otherwise have a bleak future.

By virtue of their biphasic lifestyle, all marine endotherms that come to land should be behaving so as to maximize the probability and magnitude of a positive energy budget to grow their young as quickly and efficiently as possible, although the time scale over which the said conditions must be met can be highly variable, being largely dependent on animal mass (cf. land/sea phases for elephant seals [e.g., Crocker et al. 2001] vs. cormorants [Grémillet et al. 2003]). In order to understand the solutions that species display with regard to land/water cycles (e.g., Arnould and Hindell 2001, Trites and Porter 2002), we need to elucidate the complex interactions between the factors that relate to energy expenditure (travel costs, resting costs according to the environment) and energy acquisition (the location of prey and their rate of encounter, this being modulated by their distribution and the specific search strategy, over time and space, adopted). It is clear from this work, however, that a standard solution might not occur even within a species due to different conditions occurring at different localities and even changing over time, both seasonally and over interannual scales. Modeling approaches will undoubtedly enhance our understanding of processes but ultimately cannot substitute for determination of the necessary values. Our work has shown that rates of prey acquisition are particularly critical in this regard. Fortunately, recent increases in the technology for attaching monitoring devices to animals indicate that even this is likely to be quantified in the near future (Biuw et al. 2003, Naito 2004) so that we will be able to appreciate better the complexities inherent in life history strategies of marine endotherms.

\section{ACKNOWLEDGMENTS}

This work was funded by the Deutsche Forschungsgemeinschaft and by the VW Stiftung. The work at the Falklands was made possible due to support by the Falklands Conservation and the Chater family. Grateful thanks are extended to Raul Clarke and Carlito of the Consejo Agrario de Santa Cruz for logistic support at Cabo Virgenes and, of course, to Pinocho, Leonor, José, and Nieves for moral and physical support at San Julian.

\section{Literature Cited}

Arnould, J. P. Y., and M. A. Hindell. 2001. Dive behavior, foraging locations, and maternal-attendance patterns of Australian fur seals (Arctocephallus pusillus doriferus). Canadian Journal of Zoology 79:35-48.

Badano, L. A., J. A. Scolaro, and J. A. Upton. 1982. Distribución espacial de la nidificación de Spheniscus magellanicus en Cabo Dos Bahías, Chubut, Argentina (Aves: Spheniscidae). Historia Natural 2:241-251.
Bannasch, R., R. P. Wilson, and B. Culik. 1994. Hydrodynamic aspects of design and attachment of a back-mounted device in penguins. Journal of Experimental Biology 194: 83-96.

Beck, C. A., W. D. Bowen, and J. J. Iverson. 2003. Sex differences in the seasonal patterns of energy storage in a phocid seal. Journal of Animal Ecology 72:280-291.

Benoit, R., J. L. Desgranges, and R. McNeil. 1993. Directions of arrivals of Great Blue Herons (Ardea herodias) at nests with large chicks near Montréal, Québec. Canadian Journal of Zoology 71:2250-2257.

Berthold, P. 2003. Genetic basis and evolutionary aspects of bird migration. Advances in the Study of Behavior 33:175229.

Biuw, M., B. McConnell, C. J. A. Bradshaw, H. Burton, and M. Fedak. 2003. Blubber and buoyancy: monitoring the body condition of free-ranging seals using simple dive characteristics. Journal of Experimental Biology 206:34053423.

Blough, D. S. 2002. Measuring the search image: expectation, detection, and recognition in pigeon visual search. Journal of Experimental Psychology-Animal Behavior Processes 28:397-405.

Boersma, P. D. 1997. Magellanic Penguins decline in south Atlantic. Penguin Conservation June: 2-5.

Boersma, P. D., and D. L. Stokes. 1995. Conservation: threats to penguin populations. Pages 127-139 in J. N. Davies and J. Busby, editors. The penguins. Oxford University Press, Oxford, UK.

Boersma, P. D., D. L. Stokes, and I. J. Strange. 2002. Applying ecology to conservation: tracking breeding penguins at New Island South reserve, Falkland Islands. Aquatic Conservation in Marine and Freshwater Ecosystems 12:6374.

Boersma, P. D., D. L. Stokes, and P. M. Yorio. 1990. Reproductive variability and historical change of Magellanic Penguins (Spheniscus magellanicus) at Punta Tombo, Argentina. Pages 15-43 in L. S. Davis and J. T. Darby, editors. Penguin biology. Academic Press, New York, New York, USA.

Bonnet, X., G. Naulleau, R. Shine, and O. Lourdais. 1999. What is the appropriate timescale for measuring costs of reproduction in a "capital breeder" such as the aspic viper? Evolutionary Ecology 13:485-497.

Bonnet, X., G. Naulleau, R. Shine, and O. Lourdais. 2001. Short-term versus long-term effects of food intake on reproductive output in a viviparous snake, Viera aspis. Oikos 92:297-308.

Borboroglu, P. G., P. Yorio, P. D. Boersma, H. Del Valle, and M. Bertellotti. 2002. Habitat use and breeding distribution of Magellanic Penguins in northern San Jorge Gulf, Patagonia, Argentina. Auk 119:233-239.

Boswell, J., and D. MacIvor. 1974. The Magellanic Penguin Spheniscus magellanicus. Pages 271-305 in B. Stonehouse, editor. The biology of penguins. Macmillan, New York, New York, USA.

Boyd, I. L. 2000. State-dependent fertility in pinnipeds: contrasting capital and income breeders. Functional Ecology 14:623-630.

Boyd, I. L., and J. P. Croxall. 1996. Dive durations in pinnipeds and seabirds. Canadian Journal of Zoology 74: $1696-1705$.

Brodin, A., and K. I. Jonsson. 2003. Optimal energy allocation and behavior in female raptorial birds during the nestling period. Ecoscience 10:140-150.

Burger, A. E. 1991. Maximum diving depths and underwater foraging in alcids and penguins. Canadian Wildlife Service Occasional Papers 68:9-15.

Burger, A. E. 1997. Arrival and departure behavior of Common Murres at colonies: evidence for an information halo? Colonial Waterbirds 20:55-65. 
Cannell, B. L., and J. M. Cullen. 1998. The foraging behavior of Little Penguins Eudyptula minor at different light levels. Ibis 140:467-471.

Capurro, A., E. Frere, M. Gandini, P. Gandini, T. Holik, V. Lichtschein, and P. D. Boersma. 1988. Nest density and population size of Magellanic Penguins (Spheniscus magellanicus) at Cabo Dos Bahías. Auk 105:585-588.

Carreto, J. I., H. R. Benavidez, R. M. Negri, and P. D. Glorioso. 1986. Toxic red-tide in the Argentine Sea. Phytoplankton distribution and survival of the toxic dinoflagellate Gonyaulax excavata in a frontal area. Journal of Plankton Research 8(1):15-28.

Carribero, A., D. Perez, and P. Yorio. 1995. Actualización del estado poblacional del Pingüino Patagónico Spheniscus magellanicus en Península Valdés, Chubut, Argentina. El Hornero 14:33-37.

Clausen, A. P., and K. Pütz. 2002. Recent trends in diet composition and productivity of Gentoo, Magellanic and Rockhopper Penguins in the Falkland Islands. Aquatic Conservation in Marine and Freshwater Ecosystems 12:5161.

Cooper, J. 1977. Energetic requirements for growth of the Jackass Penguin. Zoologica Africana 12:201-213.

Cousseau, M. B., and R. G. Perrotta. 1998. Peces marinos de Argentina. Biología, distribución, pesca. Instituto Nacional de Investigación y Desarrollo Pesquero (INIDEP), Mar del Plata, Argentina.

Crocker, D. E., J. D. Williams, D. P. Costa, and B. J. Le Boeuf. 2001. Maternal traits and reproductive effort in northern elephant seals. Ecology 82:3541-3555.

Culik, B. M., R. Bannasch, and R. P. Wilson. 1994a. External devices on penguins: how important is shape? Marine Biology 118:353-357.

Culik, B., J. Hennicke, and T. Martin. 2000. Humboldt Penguins outmanoeuvring El Niño. Journal of Experimental Biology 203:2311-2322.

Culik, B., R. P. Wilson, and R. Bannasch. 1994b. Underwater swimming at low energetic cost by Pygoscelid Penguins. Journal of Experimental Biology 197:65-78.

Daciuk, J. 1976. Notas faunísticas y bioecológicas de Península Valdés y Patagonia. XV. Estudio bioecológico inicial de los esfeníscidos visitantes y colonizadores de Península Valdés y costas aledañas (Prov. de Chubut, Argentina). Physis C35:43-56.

Davis, L. S., and G. D. Miller. 1992. Satellite tracking of Adélie Penguins. Polar Biology 12:503-506.

Davoren, G. K., W. A. Montevecchi, and J. T. Anderson. 2003. Search strategies of a pursuit-diving marine bird and the persistence of prey patches. Ecological Monographs 73: 463-481.

Drent, R., C. Both, M. Green, J. Madsen, and T. Piersma. 2003. Pay-offs and penalties of competing migratory schedules. Oikos 103:274-292.

Ekstrom, P. A. 2004. An advance in geolocation by light. Memoires of the National Institute for Polar Research 58: 210-226.

Fitzpatrick, L. C., C. Guerra, and R. Aguilar. 1988. Energetics of reproduction in the desert-nesting seagull Larus modestus. Estudios Oceanoligos 7:33-39.

Forero, M. G., K. A. Hobson, G. R. Bortolotti, J. A. Donázar, M. Bertellotti, and G. Blanco. 2002. Food resource utilization by the Magellanic Penguin evaluated through stableisotope analysis: segregation by sex and age and influence on offspring quality. Marine Ecology Progress Series 234: 289-299.

Frere, E. 1993. Ecología reproductiva del Pinguino de Magellanes (Spheniscus magellanicus) en la colonia de nidificación de Cabo Vírgenes. Dissertation. University of Buenos Aires, Buenos Aires, Argentina.
Frere, E., P. Gandini, and V. Lichtschein. 1996. Variación Latitudinal de la dieta del Pinguino de Magallanes (Spheniscus magellanicus) en la costa Patagonica, Argentina. Ornitologia Neotropical 7:35-41.

Furness, B. L., R. C. Laugksch, and D. C. Duffy. 1984. Cephalopod beaks and studies of seabird diets. Auk 101:619620.

Gandini, P., E. Frere, and P. D. Boersma. 1996. Status and conservation of Magellanic Penguins Spheniscus magellanicus in Patagonia, Argentina. Bird Conservation International 6:307-316.

Gandini, P., E. Frere, and T. Holik. 1992. Implicancias de las diferencias en el tamaño corporal entre colonia para el uso de medidas morfometricas como metodo del sexado en Spheniscus magellanicus. El Hornero 13:211-213.

Gauthier-Clerc, M., Y. Le Maho, Y. Clerquin, S. Drault, and Y. Handrich. 2000. Penguin fathers preserve food for their chicks. Nature 408:928-929.

Gauthier-Clerc, M., Y. Le Maho, J.-P. Gendner, J. Durant, and Y. Handrich. 2001. State-dependent decisions in long-term fasting king penguins, Aptenodytes patagonicus, during courtship and incubation. Animal Behavior 62:661-669.

Glorioso, P. D. 2000. Patagonian shelf 3D tide and surge model. Journal of Marine Systems 24:141-151.

Gochfeld, M. 1980. Timing of breeding and chick mortality in central and peripheral nests of Magellanic Penguins. Auk 97:191-193.

Gosztonyi, A. E. 1984. La alimentación del Pinguino Magellanico (Spheniscus magellanicus) en las adyacencias de Punta Tombo, Chubut, Argentina. Contribuciones del Centro Nacional Patagonico 95:1-9.

Grémillet, D., G. Wright, A. Lauder, D. N. Carss, and S. Wanless. 2003. Modelling the daily food requirements of wintering great cormorants: a bioenergetics tools for wildlife management. Journal of Applied Ecology 40:266-277.

Gudmundsson, T., and A. Gamberale. 1972. Observaciones sobre existencias aprovechables de anchoíta frente a la costa bonaerense, 1969-1970-1971. Publicaciones de Proyectos de Desarrollo Pesquero, Mar del Plata 40:1-31.

Hansen, J. E., and A. Madirolas. 1996. Distribución, evaluación acústica y estructura poblacional de la anchoíta (Engaulis anchoita). Resultados de las campañas del año 1993. Revista de Investigaciones y Desarrollos Pesqueros 10:521.

Hansen, J. E., P. Martos, and A. Madirolas. 2001. Relationship between spatial distribution of the Patagonian stock of Argentine anchovy, Engraulis anchoita, and sea temperatures during late spring to early summer. Fisheries Oceanography 10:193-206.

Heath, R. G. M., and R. M. Randall. 1985. Growth of Jackass Penguin chicks (Spheniscus demersus) hand reared on different diets. Journal of Zoology London 205:91-105.

Hedenström, A. 2003. Optimal migration strategies in animals that run: a range equation and its consequences. Animal Behavior 66:631-636.

Henry, M., D. W. Thomas, R. Vaudry, and M. Carrier. 2002. Foraging distances and home range of pregnant and lactating little brown bats (Myotis lucifugus). Journal of Mammalogy 83:767-774.

Hill, R. D. 1994. Theory of geolocation by light levels. Pages 227-236 in B. J. Le Boeuf and R. M. Laws, editors. Elephant seals: population ecology, behavior, and physiology. University of California Press, Berkeley, California, USA.

Hill, R. D., and M. J. Braun. 2001. Geolocation by light level, the next step: latitude. Pages 443-456 in J. Sibert and J. L. Nielsen, editors. Electronic tagging and tracking in marine fisheries. Kluwer Academic Publishers, Dordrecht, The Netherlands.

Hochscheid, S., and R. P. Wilson. 1999. A new method for the determination of at-sea activity in sea turtles. Marine Ecology Progress Series 185:293-296. 
Irons, D. B. 1998. Foraging area fidelity of individual seabirds in relation to tidal cycles and flock feeding. Ecology 79:647-655

Jackson, T. P. 2001. Factors influencing food collecting behavior of Brant's whistling rat (Parotomys bratsii): a central place forager. Journal of Zoology London 255:15-23.

Jonsson, K. I. 1997. Capital and income breeding as alternative tactics of resource use in reproduction. Oikos 78: 57-66.

Jonsson, K. I., J. Wiehn, and E. Korpimaki. 1999. Body reserves and unpredictable breeding conditions in the Eurasian Kestrel, Falco tinnunculus. Ecoscience 6:406-414.

Kerguelen, V., and R. T. Carde. 1997. Manoeuvres of female Brachymeria intermedia flying towards host-related odours in a wind tunnel. Physiological Entomology 22:344-356.

Kinnison, M. T., M. J. Unwin, and T. P. Quinn. 2003. Migratory costs and contemporary evolution of reproduction allocation in male chinook salmon. Journal of Evolutionary Biology 16:1257-1269.

Kooyman, G. L. 1989. Diverse divers. Springer-Verlag, Berlin, Germany.

Korpimake, E., P. Tolonen, and J. Valkama. 1994. Functionalresponses and load size effect in central place foragersdata from the kestrel and some general comments. Oikos 69:504-510.

Leopold, M. F., J. F. van Elk, and Y. M. van Heezik. 1996. Central place foraging in Oystercatchers Haematopus os tralegus: can parents that transport mussels Mytilus edulis to their young profit from size selection? Ardea 84:311325.

Lewison, R. L., and J. Carter. 2004. Exploring behavior of an unusual megaherbivore: a spatially explicit foraging model of the hippopotamus. Ecological Modelling 171: $127-138$.

Luna-Jorquera, G. 1996. Balancing the energy budget for a warm-blooded bird on a hot desert and cold seas: the case of the Humboldt Penguin. Dissertation. University of Kiel, Germany.

Luna-Jorquera, G., and B. M. Culik. 2000. Metabolic rates of swimming Humboldt Penguins. Marine Ecology Progress Series 203:301-309.

Mafraneto, A., and R. T. Carde. 1994. Fine-scale structure of pheromone plumes modulates upwind orientation of flying moths. Nature 369:142-144.

Markman, S., B. Pinshow, J. Wright, and B. P. Kotler. 2004. Food patch use by parent birds: to gather food for themselves or for their chicks? Journal of Animal Ecology 73 $747-755$.

Martos, P., and R. Sánchez. 1997. Caracterización oceanográfica de regiones frontales en la plataforma Patagonica en relación con áreas de desove y cría de la anchoíta (Engraulis anchoita). Page 30 in Abstracts Coloquio Argent. Oceanografía. IAPSO-IADO (CONICET), B. Blanca, Argentina.

Maxwell, M., and M. C. Calver. 1998. Bringing home the bacon: potential energy return from prey and central place foraging in a Willie Wagtail Rhipidura leucophrys. Emu 98: $62-65$.

McMahon, C. R., and M. Hindell. 2003. Twinning in southern elephant seals: the implications of resource allocation by mothers. Wildlife Research 30:35-39.

McNamara, J. M., and A. I. Houston. 1996. State-dependent life histories. Nature 380:215-221.

Murphy, R. C. 1936. Ocean birds of South America. Macmillan, New York, New York, USA.

Nagy, K. A., W. R. Siegfried, and R. P. Wilson. 1984. Energy utilization by free-ranging Jackass Penguins Spheniscus demersus. Ecology 65:1648-1655.

Naito, Y., editor. 2004. Bio-logging science. Memoires of the National Institute of Polar Research $\mathbf{5 8 .}$
Nevitt, G. A., and K. Haberman. 2003. Behavioral attraction of Leach's Storm-petrels (Oceanodroma leucorhoa) to dimethyl sulfide. Journal of Experimental Biology 206:14971501.

Nevitt, G. A., R. R. Veit, and P. Kareiva. 1995. Dimethyl sulfide as a foraging cue for Antarctic procellariiform seabirds. Nature 376:680-682.

Orians, G. H., and N. E. Pearson. 1979. On the theory of central place foraging. Pages 155-177 in D. J. Horn, R. Mitchell, and G. R. Stair, editors. Analysis of ecological systems. Ohio State University Press, Columbus, Ohio, USA.

Pagnoni, G., D. Perez, and M. Bertellotti. 1993. Distribución, abundancia y densidad de nidos en la Isla de los Pájaros, Chubut, Argentina. Actas II Jornadas Nacionales de Ciencias del Mar '91 Puerto Madryn, Chubut.

Palumbi, S. R. 2003. Ecological subsidies alter the structure of marine communities. Proceedings of the National Academy of Sciences 100:11927-11928.

Perez-Tris, J., and J. L. Telleria. 2002. Migratory and sedentary Blackcaps in sympatric non-breeding grounds: implications for the evolution of avian migration. Journal of Animal Ecology 71:211-224.

Perkins, J. S. 1984. Breeding ecology of Magellanic Penguins Spheniscus magellanicus at Caleta Valdés, Argentina. Cormorant 12:3-13.

Peters, G., R. P. Wilson, J. A. Scolaro, S. Laurenti, J. Upton, and H. Galleli. 1998. The diving behavior of Magellanic Penguins (Spheniscus magellanicus) at Punta Norte, Peninsula Valdés, Argentina. Colonial Waterbirds 21:1-10.

Phillips, R. A., J. R. D. Silk, J. P. Croxall, and D. R. Briggs. 2004. Accuracy of geolocation estimates for flying seabirds. Marine Ecology Progress Series 266:265-272.

Pietiainen, H., and H. Kolunen. 1993. Female body condition and breeding of the Ural Owl Strix uralensis. Functional Ecology 7:726-735.

Prince, P. A., and M. P. Harris. 1988. Food and feeding ecology of breeding Atlantic alcids and penguins. Proceedings of the International Ornithological Congress 19:11951204.

Pütz, K., R. J. Ingham, and J. G. Smith. 2000. Satellite tracking of the winter migrations of Magellanic Penguins Spheniscus magellanicus breeding in the Falkland Islands. Ibis 142:614-622.

Pütz, K., R. J. Ingham, and J. G. Smith. 2002. Foraging movements of Magellanic Penguins during the breeding season in the Falkland Islands. Aquatic ConservationMarine and Freshwater Ecosystems 12:75-87.

Quintana, F., and P. Yorio. 1997. Breeding biology of Royal and Cayenne Terns at a mixed-species colony in Patagonia. Wilson Bulletin 109:650-662.

Radl, A., and B. M. Culik. 1999. Foraging behaviour and reproductive success in Magellanic Penguins (Spheniscus magellanicus): a comparative study of two colonies in southern Chile. Marine Biology 133:381-393.

Rappole, J. H., H. Helm, and M. A. Ramos. 2003. An integrative framework for understanding the origin and evolution of avian migration. Journal of Avian Biology 34: 124-128.

Robin, J.-P., C. Fayolle, F. Decrock, M.-A. Thil, A. Côté, S. Bernard, and R. Groscolas. 2001. Restoration of body mass in King Penguins after egg abandonment at a critical energy depletion stage: early vs. late breeders. Journal of Avian Biology 32:303-310.

Ropert-Coudert, Y., C.-A. Bost, Y. Handrich, R. Bevan, P. J. Butler, A. J. Woakes, and Y. Le Maho. 2000. Impact of externally-attached loggers on the dive behaviour of the King Penguin. Physiological Biochemistry and Zoology 73:438-445. 
Ropert-Coudert, Y., R. P. Wilson, F. Daunt, and A. Kato. 2004. Patterns of energy acquisition by penguins: benefits of alternating short and long foraging trips. Behavioral Ecology 15:824-830.

SAFIRI (South African Fisheries Industrial Research Institute). 1980. Thirty-fourth annual report of the director, January-December 1980. University of Cape Town, South Africa.

Sánchez, R. P., and J. D. Deciechomski. 1995. Spawning and nursery grounds of pelagic fish species in the sea-shelf off Argentina and adjacent areas. Scientia Marina 59:455-478.

Sánchez, R. P., A. Remeslo, A. Madirolas, and J. D. Dechiechomski. 1995. Distribution and abundance of post-larvae and juveniles of the Patagonian sprat, Sprattus fuegensis, and related hydrographic conditions. Fisheries Research 23:47-81.

Schreer, J. F., and K. M. Kovacs. 1997. Allometry of diving capacity in air-breathing vertebrates. Canadian Journal of Zoology 75:339-358.

Scolaro, J. A. 1987. A model life table for Magellanic Penguins (Spheniscus magellanicus) at Punta Tombo, Argentina. Journal of Field Ornithology 58:432-441.

Scolaro, J. A. 1990. Effects of nest density on breeding success in a colony of Magellanic Penguins (Spheniscus magellanicus). Colonial Waterbirds 13:41-49.

Scolaro, J. A., and L. Arias de Reyna. 1984. Distribución espacial actualizada de la nidificación y tamaño de la población de Spheniscus magellanicus en Punta Tombo, Chubut, Argentina (Aves: Spheniscidae). Historia Natural 4: 249-256.

Scolaro, J. A., and L. A. Badano. 1986. Diet of the Magellanic Penguin (Spheniscus magellanicus) during the chickrearing period at Punta Clara, Argentina. Cormorant 13: 91-97.

Scolaro, J. A., L. A. Badano, and J. A. Upton. 1984. Estimación de la población y estructura de la nidificación de Spheniscus magellanicus en Punta Lobería, Chubut, Argentina (Aves: Spheniscidae). Historia Natural 4:229-238.

Scolaro, J. A., and O. Kovacs. 1978. El Pingüino de Magallanes (Spheniscus magellanicus). III. Nota sobre una nueva colonia de reproducción. Publicaciones Ocasionales del Instituto Biologico, Animal Serie Científica 8:1-3.

Scolaro, J. A., E. N. Rodriguez, and A. A. Monochio. 1980. El Pingüino de Magallanes (Spheniscus magellanicus). V. Distribución de las colonias de reproducción en el territorio continental Argentino. Centro Nacional Patagónico Contribución 33:1-21.

Scolaro, J. A., and A. M. Suburo. 1991. Maximum diving depths of the Magellanic Penguin. Journal of Field Ornithology 62:204-210.

Scolaro, J. A., R. P. Wilson, S. Laurenti, M. Kierspel, H. Gallelli, and J. A. Upton. 1999. Feeding preferences of the Magellanic Penguin over its breeding range in Argentina. Waterbirds 22:104-110.

Simeone, A. 2003. Humboldt Penguins (Spheniscus humboldti) in a variable environment: managing breeding and foraging strategies in the Humboldt Upwelling Ecosystem. Dissertation. University of Kiel, Germany.

Simeone, A., and R. P. Wilson. 2003. In-depth studies of Magellanic penguin (Spheniscus magellanicus) foraging: can we estimate prey consumption by perturbations in the dive profile? Marine Biology 143:825-831.

Stokes, D. L., and P. D. Boersma. 1998. Satellite tracking of Magellanic Penguin migration. Condor 100:376-381.

Tremblay, Y. 2001. Stratégies de recherche alimentaire du gorfou sauteur Eudyptes chrysocome en fonction du milieu marin prospecté. Dissertation. Université de Paris 13, France.

Trites, A. W., and B. T. Porter. 2002. Attendance patterns of Steller sea lions (Eumetopias jubatus) and their young during winter. Journal of Zoology London 256:547-556.
Venegas, C., and E. Almonacid. 1994. Alimentación del pinguino de magallanes (Spheniscus magellanicus) durante la temporada reproductiva 1992-1993 en la colonia del Seno Otway, Magallanes, Chile. Thesis. Universidad de Magallanes, Punta Arenas, Chile.

Venegas, C., and S. Sielfeld. 1981. Utilización de aves como indicatoras de presencia y potencialidad de recursos marinos eventualmente manejables. Resumen. Page 83 in Jornadas de Ciencias del Mar, Chile.

Walker, B. G., and P. D. Boersma. 2003. Diving behavior of Magellanic Penguins (Spheniscus magellanicus) at Punta Tombo, Argentina. Canadian Journal of Zoology 81:14711483.

Wanink, J. H., and L. Zwarts. 2001. Rate-maximizing optimality models predict when oystercatchers exploit a cohort of the bivalve Scrobicularia plana over a 7-year time span. Journal of Animal Ecology 70:150-158.

Watanuki, Y., and A. E. Burger. 1999. Body mass and dive duration in alcids and penguins. Canadian Journal of Zoology 77:1838-1842.

Waugh, S. M., and H. Weimerskirch. 2003. Environmental heterogeneity and the evolution of foraging behaviour in long-ranging greater albatrosses. Oikos 103:374-384.

Welch, D. W., and J. P. Eveson. 1999. An assessment of lightbased geoposition estimates from archival tags. Canadian Journal of Fisheries Aquatic Science 56:1317-1327.

Williams, T. D. 1995. The penguins. Oxford University Press, Oxford, UK.

Wilson, R. P. 1985. The Jackass Penguin Spheniscus demersus as a pelagic predator. Marine Ecology Progress Series 25:219-227.

Wilson, R. P. 1989. Diving depths of Gentoo and Adélie Penguins at Esperanza Bay, Antarctic Peninsula. Cormorant 17:1-8.

Wilson, R. P. 1995. The foraging ecology of penguins. Pages 81-106 in T. Williams, editor. The penguins. Oxford University Press, Oxford, UK.

Wilson, R. P. 1997. A restraint method for penguins. Marine Ornithology 25:72-73.

Wilson, R. P. 2002. Movements in Adélie Penguins foraging for chicks at Ardley Island, Antarctica: circles within spirals, wheels within wheels. Polar Bioscience 15:75-87.

Wilson, R. P., and B. Culik. 1992. Packages on penguins and device-induced data. Pages 573-580 in I. M. Priede and S. M. Swift, editors. Wildlife telemetry: remote monitoring and tracking of animals. Ellis Horward, Chichester, UK.

Wilson, R. P., B. Culik, H. Spairani, N. R. Coria, and D. Adelung. 1991. Depth utilization by penguins and Gentoo Penguin dive patterns. Journal für Ornithologie 132:47-60.

Wilson, R. P., J.-J. Ducamp, G. Rees, B. M. Culik, and K. Niekamp. 1992. Estimation of location: global coverage using light intensity. Pages 131-134 in I. M. Priede and S. M. Swift, editors. Wildlife telemetry: remote monitoring and tracking of animals. Ellis Horward, Chichester, UK.

Wilson, R. P., D. C. Duffy, M.-P. Wilson, and B. Araya. 1995a. Aspects of the ecology of species replacement of Humboldt and Magellanic Penguins in Chile. Le Gerfaut 85:49-61.

Wilson, R. P., W. S. Grant, and D. C. Duffy. 1986. Recording devices on free-ranging marine animals: does measurement affect foraging performance? Ecology 67:1091-1093.

Wilson, R. P., J. Kreye, K. Lucke, and H. Urquhart. 2004. Antennae on transmitters on penguins: balancing energy budgets on the high wire. Journal of Experimental Biology 207:2649-2662.

Wilson, R. P., G. D. La Cock, M.-P. Wilson, and F. Mollagee. 1985. Differential digestion of fish and squid in the Jackass Penguin Spheniscus demersus. Ornis Scandinavica 16:7779. 
Wilson, R. P., G. Peters, B. Culik, and R. Bannasch. 1996. Diving behaviour of Gentoo Penguins Pygoscelis papua; factors keeping dive profiles in shape. Marine Biology 126 153-162.

Wilson, R. P., K. Puetz, C.-A. Bost, B. M. Culik, R. Bannasch, T. Reins, and D. Adelung. 1993. Diel dive depth in penguins in relation to diel vertical migration of prey: whose dinner by candlelight? Marine Ecology Progress Series 94 $101-104$.

Wilson, R. P., K. Pütz, J.-B. Charrassin, and J. Lage. 1995 b. Artifacts arising from sampling interval in dive depth studies of marine endotherms. Polar Biology 15:575-581.

Wilson, R. P., K. Pütz, G. Peters, B. Culik, J. A. Scolaro, J.B. Charrassin, and Y. Ropert-Coudert. 1997. Long term attachment of transmitting and recording devices to penguins and other seabirds. Wildlife Society Bulletin 25:101106.

Wilson, R. P., and F. Quintana. 2004. Time for a breather: surface pauses in relation to foraging effort in imperial cormorants. Journal of Experimental Biology 207:17891796.

Wilson, R. P., Y. Ropert-Coudert, and K. Akiko. 2002. Rush and grab strategies in foraging marine endotherms: the case for haste in penguins. Animal Behaviour 63:85-95.

Wilson, R. P., J. A. Scolaro, G. Peters, S. Laurenti, M. Kierspel, H. Gallelli, and J. Upton. 1995c. Foraging areas of Magellanic Penguins, Spheniscus magellanicus, breeding at San Lorenzo, Argentina, during the incubation period. Marine Ecology Progress Series 129:1-6.

Wilson, R. P., and M.-P. Wilson. 1990. Foraging ecology of breeding Spheniscus penguins. Pages 181-206 in L. S. Da- vies and J. Darby, editors. Penguin biology. Academic Press, San Diego, California, USA.

Wilson, R. P., and M.-P. Wilson. 1995. The foraging behaviour of the African Penguin. Pages 244-265 in P. Dann, I. Norman, and P. Reilly, editors. The penguins: ecology and management. Surrey Beatty and Sons, Sidney, Australia.

Wilson, R. P., and I. Zimmer. 2004. Inspiration by Magellanic Penguins: reduced swimming effort when under pressure. Marine Ecology Progress Series 278:303-307.

Wolf, H., and R. Wehner. 2000. Pinpointing food sources: olfactory and anemotactic orientation in desert ants, $\mathrm{Ca}$ taglyphis fortis. Journal of Experimental Biology 203:857868.

Wright, J., R. E. Stone, and N. Brown. 2003. Communal roosts as structured information centres in the raven, Corvus corax. Journal of Animal Ecology 72:1003-1014.

Yorio, P., M. Bertellotti, P. García Borboroglu, A. Carribero, M. Giaccardi, M. Lizurume, P. D. Boersma, and F. Quintana. 1998. Distribución reproductiva y abundancia de las aves marinas de Chubut. Parte I: de Península Valdés a Islas Blancas. Pages 39-73 in P. Yorio, E. Frere, P. Gandini, and G. Harris, editors. Atlas de la distribución reproductiva de Aves Marinas en el litoral patagónico Argentino, Fundación Patagonia Natural.

Yudego, C., C. E. Martinez, and D. Pérez. 2000. Distribución poblacional y principales factores ecológicos que determinan la nidificación del Pingüino de Magallanes (Spheniscus magellanicus) en la colonia de San Lorenzo, Península Valdés, Chubut, Argentina. IV. Jornadas Nacionales de Ciencias del Mar, Pto. Madryn, Septiembre 2000. Resúmenes 127.

\section{APPENDIX A}

A description of the different logger types fitted to penguins is available in ESA's Electronic Data Archive: Ecological Archives M075-014-A1.

\section{APPENDIX B}

Details on the methodology of determination of penguin location and foraging ranges at sea are available in ESA's Electronic Data Archive: Ecological Archives M075-014-A2.

\section{APPENDIX C}

Details on the methods used to identify putative Magellanic foraging depths are available in ESA's Electronic Data Archive: Ecological Archives M075-014-A3.

\section{APPENDIX D}

Details on how prey length was calculated using otolith length measurements or beak rostral length are available in ESA's Electronic Data Archive: Ecological Archives M075-014-A4. 